\title{
Investigation of Catalytic Activity of a Sulfonated Aluminum-Based Metal-Organic Framework: Design of Oleic Acid Esterification With Response Surface Methodology
}

Cihan Gecgel

Mersin University

Meral Turabik ( $\nabla$ mturabik@mersin.edu.tr)

https://orcid.org/0000-0002-8345-5486

\section{Research Article}

Keywords: Metal-organic frameworks (MOFs), MIL-53(Al), sulfonated MIL-53(Al), Microwave method, esterification, Response surface methodology (RSM)

Posted Date: March 18th, 2021

DOl: https://doi.org/10.21203/rs.3.rs-321176/v1

License: (c) (i) This work is licensed under a Creative Commons Attribution 4.0 International License.

Read Full License 


\section{Abstract}

In this study, the synthesis of MIL-53(Al) (Material Institute Lavoisier, MIL) material, which is an aluminum-containing metal-organic framework (MOF) and generally produced using the solvothermal method was carried out by microwave method at different synthesis times (30-180 min) and temperatures $\left(120-180^{\circ} \mathrm{C}\right)$. In order to improve the catalytic activity of the MIL-53(Al), it was functionalized by applying sulfonation process and $\mathrm{SO}_{3}-\mathrm{MIL}-53(\mathrm{Al})$ material was also provided. It has been observed that the changing in the synthesis time and temperature cause changes in the morphologies, surface areas and thermal resistance. The highest surface area value was obtained as $1256.3 \mathrm{~m}^{2} / \mathrm{g}$ at $180^{\circ} \mathrm{C}-180$ min synthesis condition. MIL-53(Al) and $\mathrm{SO}_{3}-\mathrm{MIL}-53$ (Al) were investigated as catalysts for the esterification of the oleic acid with methanol by designing response surface methodology (RSM). The $\mathrm{SO}_{3}-\mathrm{MIL}-53(\mathrm{Al})$ catalyst provided higher conversion of oleic acid to ester than MIL-53(Al) as $97.2 \%$ and $65.9 \%$, respectively.

\section{Introduction}

Due to the increasing environmental concerns and strict regulations in the world, environmentally friendly and efficient catalytic technologies attract great attention. Liquid catalysts which are very important in the chemical and refinery industry are highly dangerous, corrosive, polluting and non-reusable in catalysis processes. For this reason, the development of highly porous solid catalysts with high activity and stability is highly desirable for both scientific and industrial aspects. Therefore, due to their high surface area, porosity and possibility to be modified and also effective usability in adsorption, separation and gas storage processes, in recent years, metal-organic frameworks (MOFs) are very popular especially in catalysis processes [1-3].

MOFs are two or three-dimensional porous structures formed by the combination of a metal (ion or cluster) and an organic binder [4]. As a subset of coordination networks, the main difference of MOFs is that they have potential voids [5]. Hundreds of different MOFs can be synthesized by replacing metal salts and organic linkers. This diversity of MOFs also enables them to be used in different application areas such as gas storage/capture, purification, separation, sensors, drug delivery, and catalysis [6-10]. There is a need for adding acidic or basic functional groups to the cage structure of MOFs, which will increase their efficiency especially in catalysis processes. Moreover, the effectiveness of MOFs in these application areas can also be increased by adding functional groups to MOFs.

MOFs are basically functionalized by two different methods: post-synthesis method (PSM) obtained by adding functional groups to MOFs structures after synthesis, and pre-functionalization method to obtain MOFs with ligands containing functional groups $[11,12]$. The pre-functionalization method is more useful and simple than the PSM method, but the variety of the PSM method makes the PSM method more important. PSM is a highly effective technique for preparing topologically identical but functionally different lattice structures [13]. 
MOFs can be synthesized by many methods such as solvothermal, microwave, sonochemical, electrochemical, mechano-chemical $[14,15]$. Generally, it is the most used is solvothermal method, because it is very useful and simple, but requires long synthesis time. The long synthesis time of the solvothermal method has increased the tendency towards alternative methods [16]. Therefore, the microwave method has become an important alternative in MOF synthesis due to its simplicity as well as the fact that the synthesis takes place in a very short time [17]. For many MOF structures, there is still no comprehensive study investigating the synthesis parameters such as temperature and time using the microwave method.

Thanks to their unique properties, the use of MOFs as catalysts has been widely studied in recent years. However, there are limited studies on the use of MOFs as catalysts in esterification which are also used in biodiesel production. Esterification process plays an important role in numerous applications such as polymers for industrial use, paints, polishes, medicines, fragrances, softeners, solvents, and synthetic rubber production [18]. Esterification reactions are carried out with the help of catalysts such as $\mathrm{H}_{2} \mathrm{SO}_{4}$, $\mathrm{HCl}$ and $\mathrm{H}_{3} \mathrm{PO}_{4}$ homogeneous acid catalysts. Recently, these homogeneous acid catalysts have been replaced by heterogeneous catalysts due to the disadvantages of separation, corrosion, environmental and reusability. Thanks to the reusability properties of heterogeneous catalysts, serious environmental and economic benefits can be achieved. In recently, thanks to their unique properties in this field, MOFs have been used extensively as a solid catalyst [3, 18-21].

One of the MOFs, $\mathrm{Al}^{3+}, \mathrm{Fe}^{3+}$ and $\mathrm{Cr}^{3+}$ based MILs (Materials of Institute Lavoisier) series can provide great advantage for esterification due to their high stability and available raw materials $[22,23]$. In this sense, MIL-53(Al), an aluminum-containing MOF, stands out with its high thermal stability and low toxicity. In this study, the synthesis of MIL-53(Al), was synthesized using microwave method at different synthesis times and temperatures. In addition, the MIL-53(Al) material was modified with post-synthetic modification (PSM) to obtain the sulfonated structure of MIL-53(Al), $\mathrm{SO}_{3}-\mathrm{MIL}-53(\mathrm{Al})$. The catalytic activities of the synthesized MIL-53 (Al) and $\mathrm{SO}_{3}-\mathrm{MIL}-53(\mathrm{Al})$ were investigated as catalysts for the esterification of oleic acid with methanol by designing with response surface methodology (RSM). Performing the design of the experiment with RSM helps to determine the effect of process variables and the interactions between all variables and provides a better understanding of the process. The effect of process variables (MetOH/OA, catalyst amount, temperature and time) on the esterification reaction and determination of the optimum reaction conditions by RSM is also studied.

\section{Material And Methods}

\subsection{Chemicals}

For the synthesis of MIL-53(Al) structures; aluminum nitrate $\left(\left(\mathrm{AlNO}_{3}\right)_{3} \cdot 9 \mathrm{H}_{2} \mathrm{O}\right.$, Acros Organics, $\left.+99 \%\right)$, terephthalic acid (TPA, Acros Organics, $+99 \%)$ and ultrapure water were used. Sulfuric acid $\left(\mathrm{H}_{2} \mathrm{SO}_{4}\right.$, Merck $98 \%$ ), trifluoromethanesulfonic anhydride (Trifilic anhydrite, $\mathrm{Tf}_{2} \mathrm{O}$, Sigma Aldrich, +99 ) and nitromethane 
$\left(\mathrm{CH}_{3} \mathrm{NO}_{2}\right.$, Acros Organics, $\left.96 \%\right)$ were used for the sulfonation process on MIL-53(Al). In the catalytic activity studies, an unsaturated fatty acid, 18-carbon oleic acid (OA, $\mathrm{C}_{18} \mathrm{H}_{34} \mathrm{O}_{2}$, Acros Organics, 99\%) and methanol were used for the esterification reactions.

\subsection{Preparation of MIL materials}

The synthesis of MIL-53(Al) was performed with the Microwave method by modifying the solvothermal method of Loiseau et al. (2004) [24]. $1 \mathrm{mmol} \mathrm{Al}\left(\mathrm{NO}_{3}\right)_{3} \cdot 9 \mathrm{H}_{2} \mathrm{O}$ and $1 \mathrm{mmol}$ TPA were placed in $100 \mathrm{~mL}$ of teflon reactor with $30 \mathrm{~mL}$ of distilled water. The reactors were held in the microwave oven for the desired test temperature and time $\left(120,150,180^{\circ} \mathrm{C}\right.$ and $30,60,120$ and $\left.180 \mathrm{~min}\right)$. At the end of the studies carried out at the specified time and temperatures, the reactors were cooled to room temperature. After reaching room temperature, it was washed with $80^{\circ} \mathrm{C} \mathrm{DMF}$ to remove unreacted $\mathrm{Al}\left(\mathrm{NO}_{3}\right)_{3}$ and TPA reagents and washed 3 times with methanol to remove DMF from the cage structure and centrifuged.

The sulfonation process on MIL-53(Al) (for $180^{\circ} \mathrm{C}-180$ min synthesis) was carried out by the postsynthesis modification method using nitromethane $\left(\mathrm{CH}_{3} \mathrm{NO}_{2}\right)$ solvent in the presence of trifluoromethanesulfonic acid (triflic anhydride, $\mathrm{Tf}_{2} \mathrm{O}$ ) [25]. For the sulfonation process, MIL53(Al) $/ \mathrm{H}_{2} \mathrm{SO}_{4} / \mathrm{Tf}_{2} \mathrm{O}$ (1/1/1.5 molar ratio) were added into $10 \mathrm{~mL}$ of nitromethane and mixed for $60 \mathrm{~min}$. Then, the mixture was filtered, the solid was washed 3 times with distilled water and once with acetone. The obtained sulfonated MIL-53(Al) material was kept in ethanol at $70^{\circ} \mathrm{C}$ for 24 hours and then in vacuum at $100^{\circ} \mathrm{C}$ for 12 hours.

\subsection{Characterization of MILs}

The Scanning Electron Microscopy (SEM) images and Energy Dispersive X-ray (EDX) analyzes of MIL materials were performed in the ZEISS Supra 55 brand scanning electron microscope. Samples were coated with platinum-palladium plating under vacuum for 15 minutes before analysis to obtain a better image. X-Ray Diffraction (XRD) analyses were performed with a Rigaku Smartlab brand powder XRD device at 2-theta angle between $3^{0}-30^{0}$ with XRF mode open at $2^{\circ} /$ min scanning speed. The FTIR spectra of the samples were recorded using with Perkin Elmer/MIR spectrophotometer and a Pike Technologies Gladi ATR accessory within the range of $450-4000 \mathrm{~cm}^{-1}$, at a resolution of $1 \mathrm{~cm}^{-1}$. Nitrogen adsorption isotherms were measured at $-196{ }^{\circ} \mathrm{C}$ using a Micromeritics Tristar Orion II 3020 surface area and porosimetry analyzer. According to the resulting isotherms of the MIL-53(Al) samples, Brunauer-EmmetTeller (BET) and Langmuir methods were used for the analysis of surface areas. Thermogravimetric analysis (TGA) were performed on a Mettler Toledo TGA/DSC 3+ thermogravimetric analyzer from room temperature to $600{ }^{\circ} \mathrm{C}$ at a ramp rate $10{ }^{\circ} \mathrm{C} / \mathrm{min}$.

\subsection{Surface acidity}

Surface acidities of synthesized MIL-53(Al) and $\mathrm{SO}_{3}-\mathrm{MIL}-53$ (Al) materials was determined by potentiometric titration of $n$-butyl amine [26, 27]. This measurement provides information on the acid 
regions of the catalyst relative to the Ei values of the initial electrode potential [26]. For measuring surface acidity, $200 \mathrm{mg}$ of catalysts was shaken in $20 \mathrm{~mL}$ of acetonitrile (ACN) for 3 hours. The suspended material was then titrated with $0.02 \mathrm{~N}, 0.05 \mathrm{~mL}$ of $\mathrm{n}$-butyl amine. Electrode potential change was measured with a digital $\mathrm{pH}$ meter in $\mathrm{mV}$ mode. The initial electrode potential indicates the acid strength of the catalyst.

\subsection{Design of Esterification Experiments with RSM}

Esterification reactions are affected by temperature change, reaction time, catalyst amount and alcohol concentration. These variables can either increase or decrease the conversion of fatty acids to esters. Therefore, it is important to determine the most favorable reaction conditions for the conversion of fatty acids to their esters and also to evaluate the influence of process variables to maximize yield and reduce costs in the ester production. The catalytic activity of the prepared catalysts was tested for the esterification of oleic acid with methanol. To optimize the esterification process, experiments were designed according to the response surface methodology (RSM) by using the Design Expert-12 statistical program. The most basic experimental design model is central composite design (CCD) which is used in the RSM. Central composite design consists of $2 k$ ( $k$ is the number of independent parameters) factorial points consisting of two axial points on each axis and some central points at a distance alpha (a) from the center of the design. Different a, i.e., different CCD can be obtained by taking the distance of the axial point from the center of the design. In this design, depending on the factor of $k$, the number of experiments $(\mathrm{N})$ was determined by the following formula:

$N=2^{k}+2 k+6(1)$

The experiments were carried out according to a central composite design with six center points for each catalyst resulting in 30 experiments. The level selection was determined according to the results obtained in pre-tests. The independent parameters of molar ratio $\left(\mathrm{x}_{1}\right)$, catalyst concentration $\left(\mathrm{x}_{2}\right)$, temperature $\left(\mathrm{x}_{3}\right)$ and time $\left(\mathrm{x}_{4}\right)$ were operated in the range of $20-100 \mathrm{mmol} / \mathrm{mmol}, 1-5 \%, 70-150{ }^{\circ} \mathrm{C}, 30-180 \mathrm{~min}$, respectively. The codes and levels of the independent variables are given in Table 1.

Esterification studies were also carried out by the microwave process. Before the esterification experiments, the MOF materials were stored in the oven at $105^{\circ} \mathrm{C}$ for 12 hours. In each study, $10 \mathrm{~mL}$ of alcohol was kept constant and the molar ratio and catalyst concentration were determined. At the end of each study, the MOF was separated from the liquid phase with 0.2 micron filters and ester conversions were determined by Gas Chromatography-Flame Ionization Detector (GC-FID, Agilent 7890A, HP Innowax column $30 \mathrm{~m} \star 250 \mu \mathrm{m} * 0.25 \mu \mathrm{m}$ ). The percent of conversion of oleic acid to ester were determined by using equation 2 from the areas of the obtained chromatograms.

conversion to ester $\%=\frac{\text { Ester peak area }}{\text { Theoretical ester full conversion peak area }} \times 100$ 


\subsection{Reusability}

Reusability studies were carried out for each catalyst at the central points of the experimental program prepared with CCD (molar ratio: $60 \mathrm{mmol}$ alcohol/mmol FA, catalyst amount: $3 \%$, temperature: $110{ }^{\circ} \mathrm{C}$ and time: $120 \mathrm{~min}$ ). After each run, the catalysts were recovered by centrifugation and washed 3 times with methanol. The recovered catalysts were dried under vacuum at $70{ }^{\circ} \mathrm{C}$ and their reusability was investigated in 3 repetitions.

\section{Results And Discussion}

First of all, MIL-53(Al), one of the MOF structures, was synthesized at different temperatures and times with the microwave method instead of the common solvothermal method in order to examine the change in synthesis yield of the materials and their textural properties. Then, the sulfonation process was performed to optimum MIL-53(Al) structure and catalytic activities of both MIL-53(Al) structures were investigated for the esterification process.

\subsection{Characterization of MIL-53(Al) Materials}

Microwave method production parameters of the synthesized MIL-53(Al) catalyst at different temperatures and times are given in Table 2. Pressure and power values naturally increased with the increasing temperature applied in the production of $100 \mathrm{~mL}$ closed Teflon reactors. The general reaction of the MIL-53(Al) formation and the obtained MOF structure is shown in Fig 1. As can be seen in the formation reaction of the MIL-53(Al) structure, $\mathrm{H}^{+}$concentration and therefore the acidity of the reaction solution will increase with the increase of conversion rate to MIL-53(Al). The final $\mathrm{pH}$ values measured after synthesis and also the calculated synthesis yield values confirm this result (Table 2). When the synthesis time and temperature increased, the synthesis yield of MIL-53(Al) is increased, but the more increase at the time and temperature, MIL-53(Al) cannot be obtained. White crystals which is specific to MIL-53(Al) could not be obtained at temperatures above $180^{\circ} \mathrm{C}$. It was not suitable for the microwave method over $180 \mathrm{~min}$.

\subsubsection{SEM-EDX analysis}

SEM images of the materials obtained in the synthesis of MIL-53(Al) at different temperatures and times are given in Fig. 2 (a-m). Synthesized MIL-53 (Al) appears as a trapezoidal crystal, similar to those previously reported in solvothermal method $[28,29]$. In Fig. 2, while the lowest crystal sizes $(300-500 \mathrm{~nm})$ are observed in the synthesis at $180^{\circ} \mathrm{C}$ for $30-180$ minutes, it is seen that the crystal sizes are between 500-800 nm in the synthesis at $120^{\circ} \mathrm{C}$ for 180 minutes. It has been reported in the literature that overmicron crystal sizes are obtained in the synthesis of MIL-53(Al) by the solvothermal method [30, 31]. SEM image of $\mathrm{SO}_{3}-\mathrm{MIL}-53(\mathrm{Al})$ material obtained by functionalization after synthesis is given in Figure $2 \mathrm{~m}$. There is no significant change in the morphology and particle size of the MIL-53 (Al) material after the sulfonation process. 
The EDX results of the synthesized MIL-53(Al) materials are given according to atomic percentages in Table 3. Elemental composition and distribution analysis by EDX measurement shows the presence of Al, $\mathrm{C}$ and $\mathrm{O}$ elements in synthesized MIL-53 (Al). Considering MIL-53 (Al) with the molecular formula $\mathrm{Al}(\mathrm{OH})$ $\left[\mathrm{O}_{2} \mathrm{C}-\mathrm{C}_{6} \mathrm{H}_{4}-\mathrm{CO}_{2}\right]$, the \% atomic $\mathrm{C} / \mathrm{Al}$ and $\mathrm{C} / \mathrm{O}$ ratios are compared to the theoretical ratios (theoretical $\mathrm{C} / \mathrm{Al}$ and $\mathrm{C} / 0$ ratios of 8.0 and 1.6 , respectively). It can be said to be closer for materials synthesized at temperatures of $180^{\circ} \mathrm{C}$. The presence of element $\mathrm{S}$ in the EDX results of $\mathrm{SO}_{3}-\mathrm{MIL}-53$ (Al) confirms the sulfonation process. The $\mathrm{C} / \mathrm{S}$ ratio shows that $54 \%$ of the aromatic terephthalate units are successfully sulfated, assuming that there is mono-sulfonation to the MIL-53(Al) structure.

\subsubsection{XRD analysis}

The XRD spectra of the MIL-53 (Al) structure and the sulfonated $\mathrm{SO}_{3}-\mathrm{MIL}-53(\mathrm{Al})$ structure are shown in Fig 3. In the XRD spectra of MIL-53(Al), the peaks at $2 \Theta=9.3,12.5$ and 17.8 degrees are among the basic peaks of MIL-53(Al) $[2,32,33]$. Peak intensities confirm the high crystallinity. Also, the XRD spectrum of the sulfonated material shows that the MIL-53(Al) lattice integrity is preserved. Sulfonated MIL-53(Al) material appears to have characteristic peaks at $2 \Theta=9.3,12.5$ and 17.8 degrees in the XRD spectrum [25, 34] reported in the literature.

\subsection{3 $\mathrm{N}_{2}$ Adsorption Isotherms}

It is important to determine textural parameters such as surface areas, pore volumes, average pore size and pore size distributions in MOF characterization. The BET surface area, Langmuir surface area, total pore volume and average pore diameter of MIL-53(Al) and $\mathrm{SO}_{3}-\mathrm{MIL}-53(\mathrm{Al})$ materials calculated from $\mathrm{N}_{2}$ adsorption isotherm data are given in Table 4. The highest BET and Langmuir surface areas of MIL53(Al) were obtained at $180^{\circ} \mathrm{C}-180 \mathrm{~min}$ synthesis as 1256.3 and $1404.3 \mathrm{~m}^{2} / \mathrm{g}$, respectively. The BET surface area for MIL-53(Al) ranges from 1000 to $1600 \mathrm{~m}^{2} / \mathrm{g}$ in the literature [24, 35-37]. Theoretically, MIL-53(Al) has a surface area of $1632.8 \mathrm{~m}^{2} / \mathrm{g}$ [33]. The pore diameters of MIL-53(Al) materials vary between 14-16 $\hat{A}$ and their total pore volume between $41-57 \mathrm{~cm}^{3} / \mathrm{g}[32,36,37]$. This shows that the synthesized MIL-53(Al) materials has been produced in large pore form. It is seen that the increase in synthesis time and temperatures cause some increase in pore volumes and diameters. The specific surface area and pore volume of the $\mathrm{SO}_{3}-\mathrm{MIL}-53(\mathrm{Al})$ were lower than those of the non-functionalized MIL53(Al), especially the $180^{\circ} \mathrm{C}-180$ min synthesis. The BET surface areas has decreased from 1404.3 to 136.2, the pore volume from 0.56 to 0.23 and the pore diameter from 16.21 to 14.50 . Although the sulfonated MIL-53(Al) structure have not differ as morphologically from the MIL-53(Al) structure, the surface areas and pore volumes have changed significantly.

Fig. 4 shows the nitrogen adsorption isotherm of MIL-53(Al) (synthesis $180{ }^{\circ} \mathrm{C}-180 \mathrm{~min}$ ) and $\mathrm{SO}_{3}-\mathrm{MIL}-$ 53(Al) structures. In Fig. 4, it is seen that the nitrogen adsorption capacity has significantly reduced after sulfonation. The isotherms obtained by nitrogen adsorption of MIL-53(Al) crystals are similar to the Type I isotherm. The similarity of the isotherms to the Type I isotherm model confirms that the synthesized 
crystals have a microporous structure. isotherms [36, 38]. As given in Fig. 4 show that the materials have a microporous.

\subsubsection{Thermogravimetric analysis}

The proportion of organic or inorganic impurities attached to the lattice structure can be determined by thermogravimetric analysis depending on the loss of weight [39]. Fig. 5 shows the TGA curves of the MIL$53(\mathrm{Al})$ and $\mathrm{SO}_{3}-\mathrm{MIL}-53(\mathrm{Al})$ materials. As seen in the TGA curves of MIL-53(Al) materials performed at 120, 150 and $180^{\circ} \mathrm{C}$ for $180 \mathrm{~min}$, the weight loss of structures occurred in 3 steps with a similar trend. Weight loss in the first step in the temperature range $60-120^{\circ} \mathrm{C} ; 5.1 \%$ for $120^{\circ} \mathrm{C}$ synthesis, $3.4 \%$ for $150{ }^{\circ} \mathrm{C}$ synthesis, $4.3 \%$ for $180^{\circ} \mathrm{C}$ synthesis. This result is due to the transition of water or solvent molecules in the pore or on the surface of the lattice structure to the gas phase [40]. The second step weight loss was determined at temperatures between $120-540{ }^{\circ} \mathrm{C}$, around $2.1 \%$ and $1.0 \%$ for synthesis at $150{ }^{\circ} \mathrm{C}$ and 180 ${ }^{\circ} \mathrm{C}$, respectively, and a little more $5.4 \%$ for a temperature of $120{ }^{\circ} \mathrm{C}$. This loss of weight is due to the removal of organic and inorganic impurities due to the cage structure. The lower values obtained in 120 ${ }^{\circ} \mathrm{C}$ production in BET surface area measurements confirm the TGA result of the lattice structure produced at $120^{\circ} \mathrm{C}$. It shows that the channels and pores in $120^{\circ} \mathrm{C}$ production cannot be completely free of impurities. The weight loss in the third step was between $540-580^{\circ} \mathrm{C}$, similarly between $34-37 \%$ of the total weight for the three substances. This step is the stage where TPA begins to decompose and the cage structure begins to degrade. The TGA curve of sulfonated MIL-53(Al) material (Fig. 5) shows that the structure is thermally stable up to a temperature slightly above $300^{\circ} \mathrm{C}$. After this temperature, it is seen that the cage structure has completely deteriorated. The first step weight loss was $45.8 \%$ at a temperature of about $300^{\circ} \mathrm{C}$. Then, weight losses in 4 different steps up to $568.7^{\circ} \mathrm{C}$, respectively, $9.4 \%$, $364.5^{\circ} \mathrm{C}, 9.2 \%, 419.5^{\circ} \mathrm{C}, 8.2 \%, 474.4^{\circ} \mathrm{C}$ and $21.6 \%, 568.7^{\circ} \mathrm{C}$ has been realized. The first step is thought to be due to the degradation of the TPA binder while the other steps are due to various impurities and Al compounds. Thermal resistance of MIL-53(Al) material has decreased significantly after sulfonation.

\subsubsection{FTIR analysis}

The FTIR spectra of the MIL-53 (Al) obtained at optimum condition ( $180^{\circ} \mathrm{C}-180 \mathrm{~min}$ ) and $\mathrm{SO}_{3}-\mathrm{MIL}-53$ (Al) structures is shown in Fig 6 . In the MIL-53(Al) spectrum, the coordination of TPA organic ligand and Al metal centers is observed with asymmetric -COO stress in the $1601 \mathrm{~cm}^{-1}$ band and symmetric -COO stress in the $1415 \mathrm{~cm}^{-1}$ band. The stress in the region of $3672 \mathrm{~cm}^{-1}$ is due to the $\mu 2-\mathrm{OH}$ stress of the $\mathrm{AlO}_{6}$ octahedra structure [24, 41-43]. The FTIR spectrum of $\mathrm{SO}_{3}-\mathrm{MIL}-53(\mathrm{Al})$ shows similarities to non-sulfated MIL-53(Al). In the $\mathrm{SO}_{3}-\mathrm{MIL}-53(\mathrm{Al})$ spectrum, the asymmetric and symmetrical -COO stresses observed in the MIL-53 (Al) material are observed in the band 1601 and $1415 \mathrm{~cm}^{-1}$, respectively. Unlike pure MIL-53 (Al) material, the $\mathrm{O}=\mathrm{S}=0$ tensile vibration in sulfated material was detected in the band of $1006 \mathrm{~cm}^{-1}$. Again, it can only be explained by the settlement of the peak sulfoxy groups in the benzene rings, which appear in the $929 \mathrm{~cm}^{-1}$ band in the sulfated sample $[25,34]$.

\subsubsection{Surface acidity}


Based on the initial electrode potential value of the catalysts, the amount of acid sites and their relative acid strength can be estimated. $\mathrm{N}$-butylamine is a strong base and can be attached to acid sites of different strengths and types, so it will titrate both the Lewis and Brønsted sites [27, 44]. Potentiometric titration curves of MIL-53(Al) materials obtained with n-butylamine are given in Fig 7. Acid strength of these sites can be classified as: Ei> $100 \mathrm{mV}$ (very strong sites), $0<\mathrm{Ei}<100 \mathrm{mV}$ (strong sites), $100<\mathrm{Ei}<0$ $\mathrm{mV}$ (weak sites) and Ei $<100 \mathrm{mV}$ (very weak sites) [26]. According to this classification, it can be said that MIL-53 (Al) and $\mathrm{SO}_{3}-\mathrm{MIL}-53$ (Al) materials have very strong acid sites. The initial electrode potential (Ei) of $\mathrm{SO}_{3}-\mathrm{MIL}-53(\mathrm{Al})(313 \mathrm{mV}$ ) material is quite high compared to MIL-53(Al) $(116 \mathrm{mV})$. In processes such as esterification, the effectiveness of catalysts depends more on the active acid sites they have. This indicates that $\mathrm{SO}_{3}-\mathrm{MIL}-53(\mathrm{Al})$ will have higher catalytic efficiency than MIL-53(Al).

\subsection{The use of MIL-53(Al) and $\mathrm{SO}_{3}-\mathrm{MIL}-53(\mathrm{Al})$ as catalysts in the esterification studies}

\subsubsection{Effect of process parameters for the response surface methodology}

Esterification is an important class of organic reactions used to produce esters from organic acids and alcohols. The catalytic efficiencies of the synthesized MIL-53(Al) and $\mathrm{SO}_{3}$-MIL-53(Al) catalysts were investigated by using microwave in the esterification experiments of oleic acid with methanol. The esterification reaction of oleic acid (OA) to methyl oleate (MO) by methanol (MetOH) is shown in Equation 3.

$\mathrm{C}_{18} \mathrm{H}_{34} \mathrm{O}_{2}+\mathrm{OH}-\mathrm{CH}_{3} \rightarrow \mathrm{C}_{19} \mathrm{H}_{36} \mathrm{O}_{2}+\mathrm{H}_{2} \mathrm{O}$

The experimental program was created with the central composite design (CCD) and molar ratio (x1), catalyst amount (x2), temperature (x3) and time (x4) was defined as coded variables. The MO conversion

$\%$ (y) was defined as the response of the process for esterification of oleic acid with MIL-53 and $\mathrm{SO}_{3}-\mathrm{MIL}$ 53 catalysts. The obtained results from CCD were given Table 5. Statistical Model Fit Summary suggested that oleic acid esterification fits the quadratic model for MIL-53(Al) catalyst and the 2 -factor interactions (2-FI) model for $\mathrm{SO}_{3}-\mathrm{MIL}-53(\mathrm{Al})$.

The obtained model fitted equations for esterification of oleic acid (OA) with MIL-53(al) and $\mathrm{SO}_{3}-\mathrm{MIL}-$ 53(Al) were shown in equations 4 and 5.

$y_{M O}=1.21 x_{1}+3.04 x_{2}+10.12 x_{3}+3.06 x_{4}-1.79 x_{3}^{2}+47.91$

$y_{M O \%}=1.729 x_{1}+2.262 x_{2}+11.22 x_{3}+3.870 x_{4}-1.79 x_{3} x_{4}+74.41$

where $\mathrm{x}_{1}$ : molar ratio MetOH/OA $(\mathrm{mmol} / \mathrm{mmol}), \mathrm{x}_{2}$ : catalyst amount $(\%), \mathrm{x}_{3}$ : temperature $\left({ }^{\circ} \mathrm{C}\right), \mathrm{x}_{4}$ : reaction time (min). The methyl ester conversion \% (y) was defined as the response of the process. When the effects of independent variables on the answers in two equations are examined, it is seen that the parameters $\mathrm{x}_{1}, \mathrm{x}_{2}, \mathrm{x}_{3}$, and $\mathrm{x}_{4}$ have positive effects on the system. The coefficients in the equations show that the most effective variable is temperature. The qualities of the models were also evaluated with the 
analysis of variance (ANOVA) and results were given in Table 6. Model $F$ values are obtained as 150.33 and 82.45 for MIL-53(Al) and $\mathrm{SO}_{3}-\mathrm{MIL}-53(\mathrm{Al})$, respectively, indicate that the models are significant. Generally, the magnitude $0.01 \%$ of $F$ values comes likely from noises. The models $p$ values less than 0.050 indicate that model terms are important. In this case, $x_{1}, x_{2}, x_{3}, x_{4}$ and $x_{3}{ }^{2}$ for MIL-53(Al), $x_{1}, x_{2}, x_{3}$, $\mathrm{x}_{4}$ and $\mathrm{x}_{3} \mathrm{x}_{4}$ for $\mathrm{SO}_{3}-\mathrm{MIL}-53(\mathrm{Al})$ are important model terms. Also, in the esterification of oleic acid with MIL-53(Al) and $\mathrm{SO}_{3}-\mathrm{MIL}-53(\mathrm{Al})$, the signal-to-noise ratio of 47.916 and 33.791 obtained is quite sufficient. It is desired that the signal-to-noise ratio showing the model sensitivity is greater than 4 .

In Fig. 8 a, b, comparison of experimental results with predicted results is given for MIL-53(Al) and $\mathrm{SO}_{3}{ }^{-}$ MIL-53(Al) ester conversions. It is seen that the experimental results and the model results are in agreement. In addition, $R\left(R^{2}\right.$ adj) values, which is the other indicator of model conformity for MIL-53(Al) and $\mathrm{SO}_{3}-\mathrm{MIL}-53(\mathrm{Al})$ catalysts, were found to be $0.969(0.962)$ and 0.945(0.933), respectively.

\subsubsection{Influence of individual parameters}

Perturbation plots given in Fig. $8 \mathrm{c}$, d show the individual effects of independent variables on response. The response of one factor was plotted by keeping the other factors constant at the center point. In both graphs for MIL-53(Al) and $\mathrm{SO}_{3}-\mathrm{MIL}-53(\mathrm{Al})$, the steeper temperature curve compared to the other curves shows that the response is more sensitive to temperature. For MetOH/OA molar ratio, it is seen in Fig. $8 \mathrm{c}$ that the increase in the MetOH/OA molar ratio does not cause a significant change in the response, especially for MIL-53(Al).

The interactive effect of temperature and reaction time of methyl oleate conversion at a constant molar ratio $\left(60 \mathrm{mmol} \mathrm{MetOH} / \mathrm{mmol} \mathrm{OA}\right.$ ) and catalyst amount ( $3 \%$ for $\mathrm{MIL}-53(\mathrm{Al})$ and $\mathrm{SO}_{3}-\mathrm{MIL}-53(\mathrm{Al})$ ) is shown in contour and 3-D plots in Fig. 9(a-d). In Figures $9 a$ and b, it can be seen that the conversion efficiency of MIL-53(Al) increases with increasing reaction time and temperature. It can also be seen in Fig $9 \mathrm{c}$ and $\mathrm{d}$ that the conversion of methyl oleate does not change significantly with increasing reaction time at a constant temperature of $150^{\circ} \mathrm{C}$. On the contrary, it is observed that the conversion to methyl oleate significantly increases with the increase in reaction time for $70^{\circ} \mathrm{C}$ temperature. This shows that the efficiency of the reaction time decreases as the temperature increases in the esterification studies with the $\mathrm{SO}_{3}-\mathrm{MIL}-53(\mathrm{Al})$ catalyst.

\subsubsection{Optimization of esterification reaction conditions}

Optimum conditions for the esterification of oleic acid with MIL-53(Al) and $\mathrm{SO}_{3}-\mathrm{MIL}-53$ catalysts were determined by Design Expert 12 software numerical optimization. In order to obtain maximum ester conversions (response), all independent parameters ( $x 1, x 2, x 3$ and $x 4)$ were set to in the test range and are shown in Table 7. In the test range, the maximum ester conversions with MIL-53 and $\mathrm{SO}_{3}-\mathrm{MIL}-53$ were determined from the model results $63.5 \%$ and $91.6 \%$, respectively. It can be seen in Table 5 that the experimental results are quite consistent with the model results. This confirms that model results can predict experimental results. In Table 5, the model results obtained by adjusting the independent variables 
as minimum and the ester conversion as maximum and the experimental results also confirm the model fit.

\subsection{Comparision of catalytic effects of MIL-53(Al) and $\mathrm{SO}_{3}-\mathrm{MIL}-53(\mathrm{Al})$ catalysts}

According to the results obtained, $\mathrm{SO}_{3}-\mathrm{MIL}-53(\mathrm{Al})$ material showed higher catalytic efficiency in the esterification of oleic acid with methanol than MIL-53(Al). This shows that in esterification reactions with MIL-53(Al) catalysts, surface acidity is effective rather than surface areas of catalysts. With MIL-53(Al) and $\mathrm{SO}_{3}-\mathrm{MIL}-53(\mathrm{Al})$, the highest ester conversions were obtained as $65.9 \%$ and $97.2 \%$, respectively, in studies conducted at temperatures of $150^{\circ} \mathrm{C}$. Table 8 presented examples of the use of some heterogeneous catalysts at different reaction conditions in the esterification of fatty acids. Catalyst amount, reaction temperature, alcohol/fatty acid ratio and reaction time are known as important parameters in esterification process. In the esterification process, the suitability of these parameters to the process should be evaluated in the selection of the appropriate catalyst. According to the heterogeneous solid catalysts used in the literature, it can be said that MIL-53(Al) catalysts are effective in ester conversions. Especially the conversions over $90 \%$ obtained with $\mathrm{SO}_{3}-\mathrm{MIL}-53(\mathrm{Al})$ material are well above the average. Although the high conversion to methyl oleate with MIL-53(Al) catalysts at high temperatures, the use of low catalyst amount is an important advantage.

\subsection{Reusability of catalysts}

One of the most important desired properties of heterogeneous catalysts is their stability in the reaction medium; the catalyst must be recyclable and reusable. Therefore, the reusability of MIL-53(Al) materials was studied in a series of three replicates and the results of all three experiments are shown in Fig 10. Reductions in conversion efficiency were observed in performing the esterification process of MIL-53(Al) and $\mathrm{SO}_{3}-\mathrm{MIL}-53(\mathrm{Al})$ catalysts at the end of three reuses. This reduction can be explained by the closure of active sites by impurities. In esterification of $\mathrm{OA}$ with methanol, at the end of the third rework, the percent of conversions decreased from $46.8 \%$ to $42.3 \%$ for MIL-53(Al) and from $77.2 \%$ to $61.4 \%$ for $\mathrm{SO}_{3}-\mathrm{MIL}-53$ (Al), respectively. These results are nevertheless satisfactory given the important advantages of heterogeneous solid catalysts over homogeneous liquid catalysts.

\section{Conclusions}

The synthesis of MIL-53(Al) has been generally carried out by the solvothermal/hydrothermal methods at $220{ }^{\circ} \mathrm{C}$ for 72 hours. In this study, MIL-53(Al) synthesis was performed using a microwave method at lower temperatures and duration. It was determined by SEM-EDX, XRD, surface area, TGA and FTIR analysis that the optimum MIL-53(Al) structure can be obtained at the $180^{\circ} \mathrm{C}-180$ min synthesis conditions. Especially, TGA and surface area results showed that the structure reached its purest form in studies performed at 180 degrees. As a detail, it was determined in the synthesis studies performed with microwave in water that the crystal sizes $(300-500 \mathrm{~nm})$ were decreased compared to the solvothermal method. 
The catalytic activity of the obtained MIL-53(Al) and $\mathrm{SO}_{3}-\mathrm{MIL}-53(\mathrm{Al})$ structures was evaluated by using the response surface method in the esterification experiments of oleic acid with methanol. According to the results obtained in the same experimental program created with CCD, the higher ester conversions were realized with the $\mathrm{SO}_{3}-\mathrm{MIL}-53(\mathrm{Al})$ compared to the MIL-53. This shows that in esterification reactions with MIL-53(Al) catalysts, surface acidity is more effective rather than surface areas of catalysts. For MIL53(Al) and $\mathrm{SO}_{3}-\mathrm{MIL}-53(\mathrm{Al})$ materials, it has been observed that the molar ratio $\mathrm{MetOH} / \mathrm{OA}\left(\mathrm{x}_{1}\right)$, catalyst amount $\left(\mathrm{x}_{2}\right)$, temperature $\left(\mathrm{x}_{3}\right)$, reaction time $\left(\mathrm{x}_{4}\right)$ coded parameters positively affect the esterification process according to the approximation functions obtained from RSM. It was determined that the most effective independent variable among the approximation function coefficients was temperature. The highest conversions were obtained as $65.9 \%$ and $97.2 \%$ for $\mathrm{MIL}-53(\mathrm{Al})$ and $\mathrm{SO}_{3}-\mathrm{MIL}-53(\mathrm{Al})$, respectively, in studies performed at temperatures of $150^{\circ} \mathrm{C}$.

It was also determined that the catalytic activity of MIL-53(Al) catalysts was slightly decreased in reusability studies. However, MIL catalysts have important advantages in terms of industrial use such as adjustability, synthesis with affordable molecules and composite formation. Considering these advantages, the results obtained with MIL-53(Al) catalysts in the esterification of oleic acid with methanol are quite satisfactory. As a result, this study investigating the synthesis, functionalization and characterization of MIL-53(Al) material, which is an Al-containing MOF, by using water at different temperatures and times with Microwave method has presented very important data to the literature.

\section{Declarations}

\section{Acknowledgements}

We would like to thank Mersin University Advanced Technology, Education, Research and Application Center (MEITAM), where we benefit from the infrastructure facilities and Mersin University Scientific Research Projects Unit (BAP) (2017-2-TP3-2621) for their financial support.

\section{References}

[1] H. Furukawa, K. E. Cordova, M. O’Keeffe, and O. M. Yaghi, Science (2013) https://doi.org/10.1126/science.1230444

[2] E. Rahmani and M. Rahmani, Ind. Eng. Chem. Res. (2018) https://doi.org/10.1021/acs.iecr.7b04206

[3] J. Jiang, F. Gándara, Y. B. Zhang, K. Na, O. M. Yaghi, and W. G. Klemperer, J. Am. Chem. Soc. (2014) https://doi.org/10.1021/ja507119n

[4] L. Hailian and O. M. Yaghi, J. Am. Chem. Soc. (1995) https://doi.org/10.1021/ja00146a033

[5] S. R. Batten, N. R. Champness, X. M. Chen, J. Garcia-Martinez, S. Kitagawa, L. Öhrström, M. O'Keeffe, P. M. Suh, J. Reedijk, Pure Appl. Chem. (2013) https://doi.org/10.1351/PAC-REC-12-11-20 
[6] Y. H. Hu and L. Zhang, Adv. Mater. (2010) https://doi.org/10.1002/adma.200902096.

[7] J. Hu, Y. Liu, J. Liu, C. Gu, and D. Wu, Microporous Mesoporous Mater. (2017) https://doi.org/10.1016/j.micromeso.2017.07.051

[8] L. Wang, J. Inorg. Organomet. Polymer. Mater. (2020) https://doi.org/10.1007/s10904-019-01186-0

[9] H. Nabipour, B. Soltani, and N. Ahmadi Nasab, J. Inorg. Organomet. Polym. Mater. (2018) https://doi.org/10.1007/s10904-018-0781-3

[10] X. Liu, H. Li, H. Pan, H. Zhang, S. Huang, K. Yang, W. Xue, S. Yang, J. Energy Chem. (2016) https://doi.org/10.1016/j.jechem.2016.01.015

[11] X. Zhao, Y Wei, H. Zhao, Z. Gao, Y. Zhang, L. Zhi, Y. Wang, H. Huang, J. Colloid Interface (2018) https://doi.org/10.1016/j.jcis.2017.12.041

[12] Z. Wang and S. M. Cohen, Chem. Soc. Rev.( 2009) https://doi.org/10.1039/b802258p

[13] K. K. Tanabe and S. M. Cohen, Chem. Soc. Rev. (2011) https://doi.org/10.1039/c0cs00031k

[14] Y. R. Lee, J. Kim, and W. S. Ahn, Korean J. Chem. Eng. (2013) https://doi.org/10.1007/s11814-0130140-6

[15] V. R. Remya and M. Kurian, Int. Nano Lett. (2019) https://doi.org/10.1007/s40089-018-0255-1

[16] J. Bedia, V. Muelas-Ramos, M. Peñas-Garzón, A. Gómez-Avilés, J. J. Rodríguez, and C. Belver, Catalysts (2019) https://doi.org/10.3390/catal9010052

[17] D. Y. Hong, Y. K. Hwang, C. Serre, G. Férey, and J. S. Chang, Adv. Funct. Mater. (2009) https://doi.org/10.1002/adfm.200801130

[18] K. Zhou and S. Chaemchuen, Int. J. Environ. Sci. Dev. (2016) https://doi.org/10.18178/ijesd.2017.8.4.957

[19] Z. Hasan, J. W. Jun, and S. H. Jhung, Chem. Eng. J. (2014) https://doi.org/10.1016/j.cej.2014.09.025

[20] F. G. Cirujano, A. Corma, and F. X. Llabrés i Xamena, Catal. Today (2015) https://doi.org/10.1016/j.cattod.2014.08.015

[21] X. Liao, X. Wang, F. Wang, Y. Yao, S. Lu, J. Inorg. Organomet. Polym. Mater. (2021) http://dx.doi.org/10.1007/s10904-020-01808-y

[22] K. Leus, Y.-Y. Liu, and P. Van Der Voort, Catal. Rev. (2014) https://doi.org/10.1080/01614940.2014.864145 
[23] Q. Xie, Y. Li, Z. Lv, H. Zhou, X. Yang, J. Chen, H. Guo, Sci. Rep. (2017) https://doi.org/10.1038/s41598017-03526-x

[24] T. Loiseau. C. Serre, C. Huguenard G. Fink, F. Taulelle M. Henry, T. Bataille, G. Ferey, Chem. Eur. J. (2004) https://doi.org/10.1002/chem.200305413

[25] M. G. Goesten J. Juan-Alcañiz, E.V. Ramos-Fernandez, K.B.S.S. Gupta, E. Stavitski, H.V. Bekkum, J. Gascon, F. Kapteijn, J. Catal. (2011) https://doi.org/10.1016/j.jcat.2011.04.015

[26] M. Nasouh Alaya and M. A. Rabah, Arab. J. Chem. (2017)

https://doi.org/10.1016/j.arabjc.2012.11.012

[27] M. N. Alaya and M. A. Rabah, J. Alloys Compd. (2013) https://doi.org/10.1016/j.jallcom.2013.05.145

[28] B. Seoane, S. Sorribas, Á. Mayoral, C. Téllez, and J. Coronas, Microporous Mesoporous Mater (2015) http://dx.doi.org/10.1016/j.micromeso.2014.10.016

[29] H. R. Abid, Z. H. Rada, J. Shang, and S. Wang, Polyhedron (2016)

http://dx.doi.org/10.1016/j.poly.2016.06.034

[30] M. Amirilargani R. B. Merlet, P. Hedayati, A. Nijmeijer, L. Winnubst, L. C. P. M. de Smet, Ernst J. R.

Sudhölter, Chem. Commun. (2019) https://doi.org/10.1039/c9cc01624d

[31] V. Finsy, L. Ma, L. Alaerts, D. E. De Vos, G. V. Baron, and J. F. M. Denayer, Microporous Mesoporous Mater. ( 2009) https://doi.org/10.1016/j.micromeso.2008.11.007

[32] W. P. Mounfield and K. S. Walton, J. Colloid Interface Sci. (2015)

https://doi.org/10.1016/j.jcis.2015.01.027

[33] C. Li, Z. Xiong, J. Zhang, and C. Wu, J. Chem. Eng. Data (2015)

https://doi.org/10.1021/acs.jced.5b00692

[34] G. L. Han, Z. Chen, L. F. Cai, Y. H. Zhang, J. F. Tian, H. H. Ma, S. M. Fang, Sep. Purif. Technol. (2019) https://doi.org/10.1016/j.seppur.2019.03.065

[35] J. Liu, F. Zhang, X. Zou, G. Yu, N. Zhao, S. Fan and G. Zhu, Chem. Commun. (2013) https://doi.org/10.1039/c3cc42287a

[36] A. Taheri, E. G. Babakhani, and J. Towfighi, Adsorpt. Sci. Technol. (2018) https://doi.org/10.1177/0263617416688690

[37] X. D. Do, V. T. Hoang, and S. Kaliaguine, Microporous Mesoporous Mater. (2011) https://doi.org/10.1016/j.micromeso.2010.07.024 
[38] J. Ge, L. Liu, L. Qiu, X. Jiang, and Y. Shen, J. Porous Mater. (2016) https://doi.org/10.1007/s10934016-0142-y

[39] M. Sánchez-Sánchez, N. Getachew, K. Díaz, M. Díaz-García, Y. Chebude, and I. Díaz, Green Chem., (2015) https://doi.org/10.1039/c4gc01861c

[40] D. K. Panchariya, R. K. Rai, S. K. Singh, and E. A. Kumar, Mater. Today Proc.

https://doi.org/10.1016/j.matpr.2017.01.037

[41] D. Xuan-dong, H. Vinh-thang, and S. Kaliaguine, Microporous Mesoporous Mater. (2011)

https://doi.org/10.1016/j.micromeso.2010.07.024

[42] D. Himsl, D. Wallacher, and M. Hartmann, Angew. Chemie - Int. Ed. (2009)

https://doi.org/10.1002/anie.200806203

[43] M. Meilikhov, K. Yusenko and R. A. Fischer, J. Chem. Soc. Dalt. Trans.(2009)

https://doi.org/10.1039/b820882b

[44] P. Villabrille, P. Vázquez, M. Blanco, and C. Cáceres, J. Colloid Interface Sci. (2002)

https://doi.org/10.1006/jcis.2002.8391

[45] B. M. Omar, M. Bita, I. Louafi, and A. Djouadi, MethodsX, (2018)

https://doi.org/10.1016/j.mex.2018.03.004

[46] G. J. Gomes, D. M. Dal Pozzo, M. F. Zalazar, M. B. Costa, P. A. Arroyo, and P. R. S. Bittencourt, Top. Catal. (2019) https://doi.org/10.1007/s11244-019-01172-3

[47] Z. Gao, S. Tang, X. Cui, S. Tian, and M. Zhang, Fuel (2015) https://doi.org/10.1016/j.fuel.2014.10.012

[48] J. Y. Park, D. K. Kim, and J. S. Lee, Bioresour. Technol. (2010)

https://doi.org/10.1016/j.biortech.2009.03.035

[49] K. H. Chung and B. G. Park, J. Ind. Eng. Chem. (2009) https://doi.org/10.1016/j.jiec.2008.11.012

[50] A. A. Costa, P. R. S. Braga, J. L. De MacEdo, J. A. Dias, and S. C. L. Dias, Microporous Mesoporous Mater. (2012) https://doi.org/10.1016/j.micromeso.2011.06.008

[51] I. K. Mbaraka, D. R. Radu, V. S. Y. Lin, and B. H. Shanks, J. Catal. (2003)

https://doi.org/10.1016/S0021-9517(03)00193-3

[52] K. Narasimharao D.R.Brown, A.F.Lee, A.D.Newman, P.F.Siril, S.J.Tavener, K.Wilson, J. Catal. (2007) https://doi.org/10.1016/j.jcat.2007.02.016

[53] J. L. Ropero-Vega, A. Aldana-Pérez, R. Gómez, and M. E. Niño-Gómez, Appl. Catal. A Gen. (2010) https://doi.org/10.1016/j.apcata.2010.02.020 
[54] K. Jiang, D. Tong, J. Tang, R. Song, and C. Hu, Appl. Catal. A Gen. (2010)

https://doi.org/10.1016/j.apcata.2010.08.062

\section{Tables}

Table 1. The levels and codes of independent parameters in the Central Composite Design (CCD).

\begin{tabular}{|llllll|}
\hline Parameters, symbols & \multicolumn{7}{c|}{ Coded levels } \\
\cline { 2 - 6 } & $\mathbf{- 2}$ & $\mathbf{- 1}$ & $\mathbf{0}$ & $\mathbf{+ 1}$ & $\mathbf{+ 2}$ \\
\hline Molar ratio (alcohol/FA, mol/mol), $x_{1}$ & 20 & 40 & 60 & 80 & 100 \\
\hline Catalyst concentration $(\%), x_{2}$ & 1 & 2 & 3 & 4 & 5 \\
\hline Temperature, $\left({ }^{\circ} \mathrm{C}\right), x_{3}$ & 70 & 90 & 110 & 130 & 150 \\
\hline Time $(\mathrm{min}), \mathrm{x}_{4}$ & 30 & 60 & 90 & 120 & 150 \\
\hline
\end{tabular}

Table 2. MIL-53(Al) synthesis parameters and microwave method operating conditions (Initial solution pH 3 3.5).

\begin{tabular}{|c|c|c|c|c|}
\hline $\begin{array}{l}\text { Temp.-time } \\
{ }^{\circ} \mathrm{C} \text {-min }\end{array}$ & $\begin{array}{l}\text { power } \\
\text { watt }\end{array}$ & $\begin{array}{l}\text { Pressure, } \\
\text { psi }\end{array}$ & $\begin{array}{l}\text { Synthesis yield } \\
\%\end{array}$ & Final $\mathrm{pH}$ \\
\hline $120-30$ & $100-110$ & $10-12$ & 50.8 & 1.9 \\
\hline $120-60$ & $100-110$ & $10-12$ & 62.5 & 1.7 \\
\hline $120-120$ & $100-110$ & $10-12$ & 70.1 & 1.5 \\
\hline $120-180$ & $100-110$ & $10-12$ & 75.3 & 1.3 \\
\hline $150-30$ & $340-380$ & $60-65$ & 54.3 & 1.4 \\
\hline $150-60$ & $340-380$ & $60-65$ & 65.6 & 1.3 \\
\hline $150-120$ & $340-380$ & $60-65$ & 75.5 & 1.2 \\
\hline $150-180$ & $340-380$ & $60-65$ & 78.2 & 1.1 \\
\hline $180-30$ & $450-500$ & $150-160$ & 55.6 & 1.3 \\
\hline $180-60$ & $450-500$ & $150-160$ & 67.5 & 1.2 \\
\hline $180-120$ & $450-500$ & $150-160$ & 78.3 & 1.1 \\
\hline $180-180$ & $450-500$ & $150-160$ & 80.2 & 1.0 \\
\hline
\end{tabular}

Table 3. EDX results of MIL-53 (Al) at different temperatures - times and $\mathrm{SO}_{3}-\mathrm{MIL}-53(\mathrm{Al})$. 


\begin{tabular}{|c|c|c|c|c|c|}
\hline Temperature-time & C & $\mathrm{O}$ (\% at.) & $\mathrm{Al}(\%$ at.) & & \\
\hline${ }^{\circ} \mathrm{C}-\min$ & (\% at.) & $(\mathrm{C} / 0)$ & $(\mathrm{C} / \mathrm{Al})$ & (\% at. ) & (\% at.) \\
\hline $120-30$ & 56.19 & $33.14(1.69)$ & $7.75(7.25)$ & 1.23 & 1.69 \\
\hline $120-60$ & 57.04 & $33.60(1.70)$ & $7.56(7.54)$ & 0.63 & 1.25 \\
\hline $120-120$ & 54.99 & $36.33(1.51)$ & $6.81(8.07)$ & 0.62 & 1.24 \\
\hline $120-180$ & 55.93 & 33.85 (1.65) & $8.67(6.45)$ & 0.45 & 1.41 \\
\hline $150-30$ & 56.60 & $34.61(1.63)$ & $7.41(7.64)$ & 0.38 & 1.18 \\
\hline $150-60$ & 57.39 & $33.86(1.69)$ & $7.85(7.31)$ & 0.36 & 1.14 \\
\hline $150-120$ & 54.82 & $35.88(1.52)$ & $7.71(7.11)$ & 0.37 & 1.46 \\
\hline $150-180$ & 55.04 & $36.01(1.53)$ & $7.47(7.36)$ & 0.38 & 1.09 \\
\hline $180-30$ & 56.07 & $34.64(1.61)$ & $7.35(7.63)$ & 0.47 & 1.47 \\
\hline $180-60$ & 56.23 & $34.50(1.62)$ & $7.46(7.53)$ & 0.42 & 1.40 \\
\hline $180-120$ & 55.52 & $34.77(1.61)$ & $7.59(7.31)$ & 0.47 & 1.63 \\
\hline $180-180$ & 56.88 & $35.42(1.61)$ & $7.39(7.69)$ & 0.43 & 1.69 \\
\hline $\mathrm{SO}_{3}-\mathrm{MIL}-53(\mathrm{Al})$ & 51.36 & 35.11 & $6.90(S=3.69 \%)$ & 1.39 & 1.55 \\
\hline
\end{tabular}

Table 4. Surface areas and porosity results of MIL-53(Al) at different temperatures - times and $\mathrm{SO}_{3}-\mathrm{MIL}-$ 53(Al) materials. 


\begin{tabular}{|lllll|}
\hline $\begin{array}{l}\text { Temperature-time } \\
{ }^{\circ} \mathrm{C}-\mathrm{min}\end{array}$ & $\begin{array}{l}\text { BET surface area } \\
\left(\mathrm{m}^{2} / \mathrm{g}\right)\end{array}$ & $\begin{array}{l}\text { Langmuir surface area } \\
\left(\mathrm{m}^{2} / \mathrm{g}\right)\end{array}$ & $\begin{array}{l}\text { Pore volume } \\
\left(\mathrm{cm}^{3} / \mathrm{g}\right)\end{array}$ & $\begin{array}{l}\text { Pore dia. } \\
(\hat{A})\end{array}$ \\
\hline $120-30$ & 812.3 & 925.1 & 0.45 & 14.77 \\
\hline $120-60$ & 1042.2 & 1179.7 & 0.48 & 14.57 \\
\hline $120-120$ & 1083.3 & 1192.8 & 0.51 & 14.44 \\
\hline $120-180$ & 1088.7 & 1179.3 & 0.52 & 14.98 \\
\hline $150-30$ & 1098.7 & 1130.9 & 0.55 & 15.01 \\
\hline $150-60$ & 1122.2 & 1150.1 & 0.54 & 15.75 \\
\hline $150-120$ & 1139.3 & 1178.9 & 0.57 & 16.78 \\
\hline $150-180$ & 1192.6 & 1310.7 & 0.55 & 15.10 \\
\hline $180-30$ & 1230.1 & 1291.4 & 0.53 & 15.12 \\
\hline $180-60$ & 1220.9 & 1280.1 & 0.53 & 15.18 \\
\hline $180-120$ & 1208.7 & 1292.6 & 0.56 & 16.13 \\
\hline $180-180$ & 1256.3 & 1404.3 & 0.55 & 16.21 \\
\hline SO ${ }_{3}-\mathrm{MIL}-53(\mathrm{Al})$ & 136.2 & 164.2 & 0.26 & 14.50 \\
\hline
\end{tabular}

Table 5. CCD experiment program and results. 


\begin{tabular}{|c|c|c|c|c|c|c|}
\hline \multirow[t]{3}{*}{ run } & \multicolumn{4}{|l|}{ Coded levels } & \multicolumn{2}{|c|}{ Response (y) } \\
\hline & $x_{1}$ & $x_{2}$ & $x_{3}$ & $\mathrm{x}_{4}$ & MIL-53(Al) & $\mathrm{SO}_{3}-\mathrm{MIL}-53(\mathrm{Al})$ \\
\hline & $\mathrm{mmol} / \mathrm{mmol}$ & $\%$ & ${ }^{\circ} \mathrm{C}$ & $\min$ & $\mathrm{MO} \%$ & MO\% \\
\hline 1 & 60 & 3 & 110 & 120 & 47.5 & 77.1 \\
\hline 2 & 80 & 4 & 130 & 90 & 57.1 & 83.3 \\
\hline 3 & 40 & 4 & 130 & 150 & 59.1 & 86.5 \\
\hline 4 & 40 & 4 & 90 & 90 & 35.8 & 57.1 \\
\hline 5 & 60 & 3 & 110 & 120 & 48.1 & 76.8 \\
\hline 6 & 20 & 3 & 110 & 120 & 45.5 & 72.1 \\
\hline 7 & 60 & 3 & 110 & 120 & 47.8 & 74.2 \\
\hline 8 & 100 & 3 & 110 & 120 & 50.5 & 78.9 \\
\hline 9 & 80 & 4 & 90 & 90 & 38.2 & 61.5 \\
\hline 10 & 60 & 3 & 150 & 120 & 65.9 & 97.2 \\
\hline 11 & 80 & 2 & 130 & 90 & 50.8 & 81.2 \\
\hline 12 & 80 & 2 & 90 & 150 & 40.2 & 77.1 \\
\hline 13 & 60 & 5 & 110 & 120 & 56.5 & 83.5 \\
\hline 14 & 60 & 3 & 110 & 120 & 50.1 & 75.3 \\
\hline 15 & 40 & 4 & 130 & 90 & 53.1 & 85.7 \\
\hline 16 & 80 & 2 & 130 & 150 & 55.5 & 85.6 \\
\hline 17 & 60 & 3 & 110 & 180 & 54.5 & 81.1 \\
\hline 18 & 80 & 2 & 90 & 90 & 31.5 & 56.6 \\
\hline 19 & 40 & 2 & 90 & 90 & 27.9 & 53.5 \\
\hline 20 & 40 & 2 & 130 & 90 & 48.1 & 79.8 \\
\hline 21 & 60 & 3 & 110 & 120 & 47.9 & 75.6 \\
\hline 22 & 60 & 3 & 70 & 120 & 16.9 & 50.5 \\
\hline 23 & 60 & 3 & 110 & 120 & 48.1 & 77.1 \\
\hline 24 & 80 & 4 & 90 & 150 & 41.4 & 68.3 \\
\hline 25 & 60 & 3 & 110 & 60 & 41.7 & 65.8 \\
\hline 26 & 40 & 2 & 130 & 150 & 53.8 & 84.5 \\
\hline
\end{tabular}




\begin{tabular}{|lllllll|}
27 & 40 & 2 & 90 & 150 & 38.2 & 61.5 \\
\hline 28 & 60 & 1 & 110 & 120 & 40.5 & 66.4 \\
\hline 29 & 40 & 4 & 90 & 150 & 40.8 & 67.3 \\
\hline 30 & 80 & 4 & 130 & 150 & 61.3 & 90.2 \\
\hline
\end{tabular}

Table 6. ANOVA results of the models obtained by CCD

\begin{tabular}{|c|c|c|c|c|c|c|c|c|}
\hline \multirow[t]{2}{*}{ Source } & \multicolumn{4}{|c|}{ MIL-53(Al) } & \multicolumn{4}{|c|}{$\mathrm{SO}_{3}-\mathrm{MIL}-53(\mathrm{Al})$} \\
\hline & $\begin{array}{l}\text { Sum of } \\
\text { squares }\end{array}$ & df & $\begin{array}{l}\text { F- } \\
\text { value }\end{array}$ & $P$ value & $\begin{array}{l}\text { Sum of } \\
\text { squares }\end{array}$ & df & $\begin{array}{l}\text { F- } \\
\text { value }\end{array}$ & $P$ value \\
\hline Model & 3029.04 & 5 & 150.33 & $\begin{array}{l}<.0001 \\
0.00\end{array}$ & 3582.75 & 5 & 82.45 & $\hat{0}_{0.0001}$ \\
\hline$x 1$ & 35.53 & 1 & 8.82 & 0.0067 & 71.76 & 1 & 8.26 & 0.0084 \\
\hline$x 2$ & 220.83 & 1 & 54.80 & $\begin{array}{l}< \\
0.0001\end{array}$ & 122.85 & 1 & 14.14 & 0.0010 \\
\hline$x 3$ & 2456.33 & 1 & 609.55 & $\begin{array}{l}< \\
0.0001\end{array}$ & 2977.05 & 1 & 342.54 & $\begin{array}{l}< \\
0.0001\end{array}$ \\
\hline$x 4$ & 224.48 & 1 & 55.71 & $\begin{array}{l}< \\
0.0001\end{array}$ & 359.60 & 1 & 41.38 & $<_{0.0001}^{<}$ \\
\hline$x 3 \times 4$ & - & - & - & - & 51.48 & 1 & 5.92 & 0.0228 \\
\hline$x 3^{2}$ & 91.88 & 1 & 22.80 & $\begin{array}{l}<.0001 \\
0\end{array}$ & - & - & - & - \\
\hline Residual & 96.71 & 24 & & & 208.58 & 24 & & \\
\hline $\begin{array}{l}\text { Lack of } \\
\text { fit }\end{array}$ & 92.36 & 19 & 5.58 & 0.0329 & 201.64 & 19 & 7.64 & 0.0166 \\
\hline $\begin{array}{l}\text { Pure } \\
\text { error }\end{array}$ & 4.35 & 5 & & & 6.95 & 5 & & \\
\hline Cor Total & 3125.75 & 29 & & & 3791.33 & 29 & & \\
\hline
\end{tabular}

Table 7. The predicted and actual values of the parameters and responses obtained from RSM for esterification of oleic acid with MIL-53(Al) and $\mathrm{SO}_{3}-\mathrm{MIL}-53(\mathrm{Al})$ catalysts. 


\begin{tabular}{|lllllll|}
\hline Parameters & X1 & X2 & X3 & X4 $(\mathrm{min})$ & MIL-53(Al) & SO $_{3}$-MIL-53(Al) \\
& $(\mathrm{mmol} / \mathrm{mmol})$ & $(\%)$ & $\left({ }^{\circ} \mathrm{C}\right)$ & & $\mathrm{MO} \%$ & $\mathrm{MO} \%$ \\
\hline Predicted & 40 & Min. & Min. & Min. & Max. & Max. \\
\hline Actual & 40 & 2 & 112 & 90 & 41.7 & 68.0 \\
\hline & Test range & Test & Test range & Test range & Max. & Max. \\
\hline Predicted & 80 & range & & & & \\
\hline $\begin{array}{l}\text { Actual (run } \\
\text { 30) }\end{array}$ & 80 & 4 & 130 & 150 & 63.5 & 91.6 \\
\hline
\end{tabular}

Min.:Minimum, Max: Maximum

Table 8. Comparison of the esterification studies with some heterogeneous solid catalysts. 


\begin{tabular}{|c|c|c|c|c|c|c|}
\hline Catalyst & $\begin{array}{l}\text { Molar } \\
\text { ratio } \\
\text { (Alcohol } \\
\text { /FA) }\end{array}$ & Alcohol/FA & $\begin{array}{l}\text { time } \\
\text { (h) }\end{array}$ & $\begin{array}{l}\text { Temp. } \\
\left({ }^{\circ} \mathrm{C}\right)\end{array}$ & $\begin{array}{l}\text { Catalyst } \\
\text { amount \% }\end{array}$ & $\begin{array}{l}\text { Conversion } \\
\%\end{array}$ \\
\hline H-ZSM5 (Si/Al 25) [45] & 16 & MetOH :OA & 1.5 & 60 & 1 & 80 \\
\hline ZSM5 [45] & 4.5 & MetOH:OA & 2 & 70 & 10 & 76 \\
\hline $\mathrm{H}-\mathrm{Y}-80[46]$ & 3 & MetOH :OA & 3 & 100 & 10 & 92 \\
\hline S-OMC [47] & 10 & MetOH:OA & 8 & 100 & 20 & 96 \\
\hline Amberlyst-BD20 [48] & 6 & MetOH:OA & 3 & 80 & 16 & 93 \\
\hline Amberlyst-15 [48] & 6 & MetOH:OA & 3 & 80 & 16 & 96 \\
\hline H-MFI (Si/Al=25)[49] & 16 & MetOH:OA & 3 & 60 & 27 & 80 \\
\hline H-MOR(Si/Al=10)[49] & 16 & MetOH:OA & 3 & 60 & 19 & 82 \\
\hline $\mathrm{H}-\mathrm{Y}(\mathrm{Si} / \mathrm{Al}=5)[50]$ & 6 & EtOH: OA & 2 & 200 & 19 & 74 \\
\hline $\begin{array}{l}\text { \%6 WO3/H-Y(Si/Al=5) } \\
\text { [50] }\end{array}$ & 6 & EtOH: OA & 2 & 200 & 19 & 80 \\
\hline SBA15- $\mathrm{C}_{3} \mathrm{H}_{6}-\mathrm{SO}_{3} \mathrm{H}[51]$ & 160 & MetOH: PA & 3 & 85 & 10 & 80 \\
\hline $\mathrm{SBA} 15-\mathrm{Ph}-\mathrm{SO}_{3} \mathrm{H}[51]$ & 160 & MetOH: PA & 3 & 85 & 10 & 93 \\
\hline $\mathrm{Cs}_{2.3} \mathrm{PW}_{12} \mathrm{O}_{40}[52]$ & 30 & MetOH:PA & 3 & 60 & 1.9 & 73 \\
\hline $\mathrm{Cs}_{2.3} \mathrm{PW}_{12} \mathrm{O}_{40}[52]$ & 30 & MetOH:PA & 6 & 60 & 1.9 & 100 \\
\hline $\begin{array}{l}\text { Sulfated }\left[\mathrm{SO}_{4}{ }^{2-} / \mathrm{TiO}_{2}\right] \\
{[53]}\end{array}$ & 10 & EtOH:OA & 2 & 80 & 2 & 69 \\
\hline $\begin{array}{l}\text { Sulfated }\left[\mathrm{SO}_{4}{ }^{2-} / \mathrm{TiO}_{2}\right] \\
{[53]}\end{array}$ & 10 & EtOH:OA & 3 & 80 & 2 & 83 \\
\hline $\begin{array}{l}\mathrm{SO}_{4}{ }^{2-} / \mathrm{ZrO}_{2}{ }^{-} \mathrm{MoO}_{3}- \\
\mathrm{Nd}_{2} \mathrm{O}_{3}[54]\end{array}$ & 9 & MetOH:OA & 2 & 65 & 10 & 90 \\
\hline $\begin{array}{l}\mathrm{SO}_{4}{ }^{2-} / \mathrm{ZrO}_{2}{ }^{-} \mathrm{MoO}_{3}- \\
\mathrm{Nd}_{2} \mathrm{O}_{3}[54]\end{array}$ & 9 & MetOH:OA & 4 & 65 & 10 & 98 \\
\hline MIL-53(Al)(this work) & 60 & MetOH:OA & 2 & 150 & 3 & 65.9 \\
\hline $\begin{array}{l}\mathrm{SO}_{3} \text {-MIL-53(Al) (this } \\
\text { work) }\end{array}$ & 60 & MetOH: OA & 2 & 150 & 3 & 97.2 \\
\hline
\end{tabular}

FA: Fatty acid, OA: Oleic acid, PA: Palmitic acid, LA: Lauric acid, MetOH: Methanol, EtOH: Ethanol 
Figures

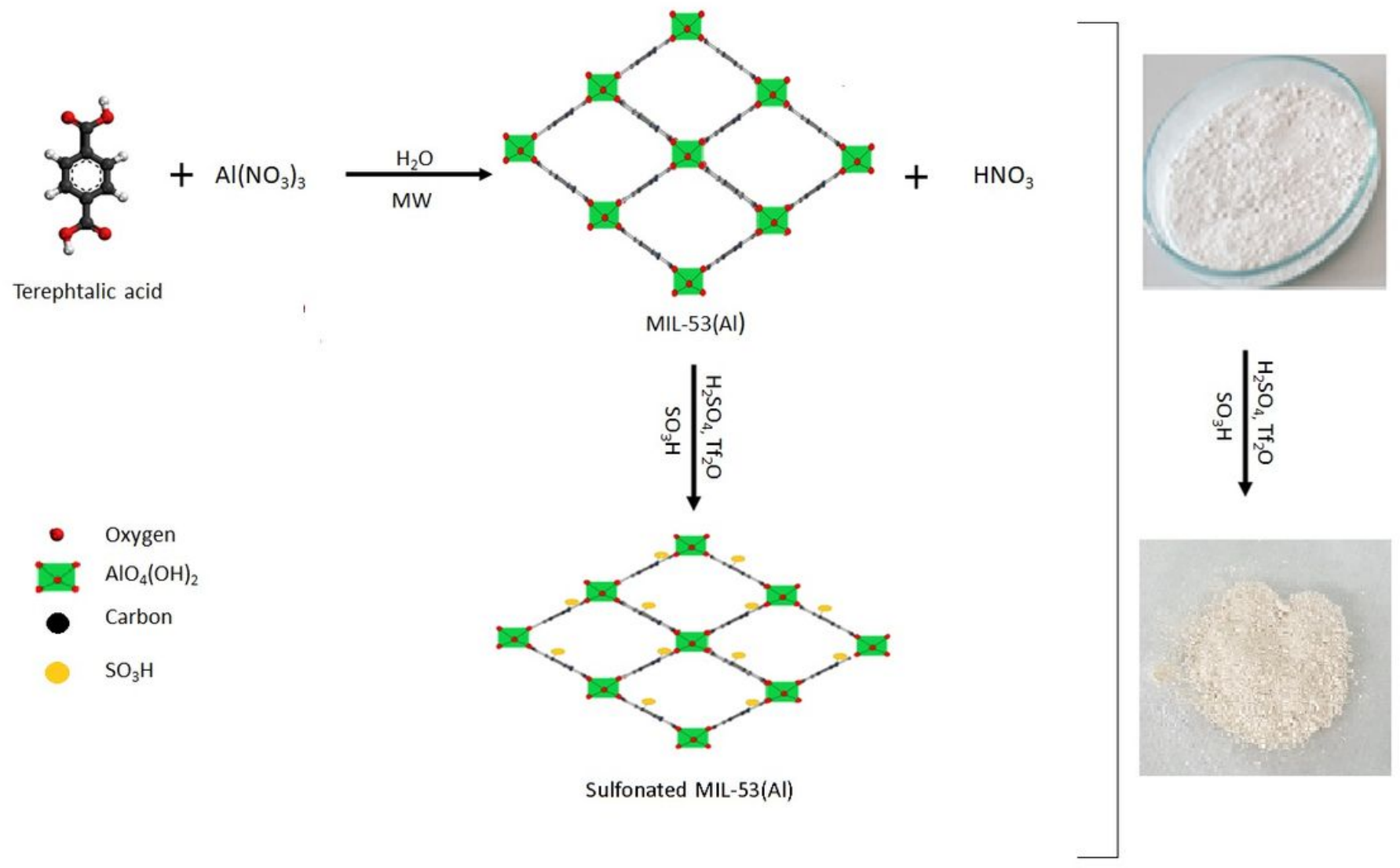

\section{Figure 1}

The formation of MIL-53(Al) and S03-MIL-53(Al) 

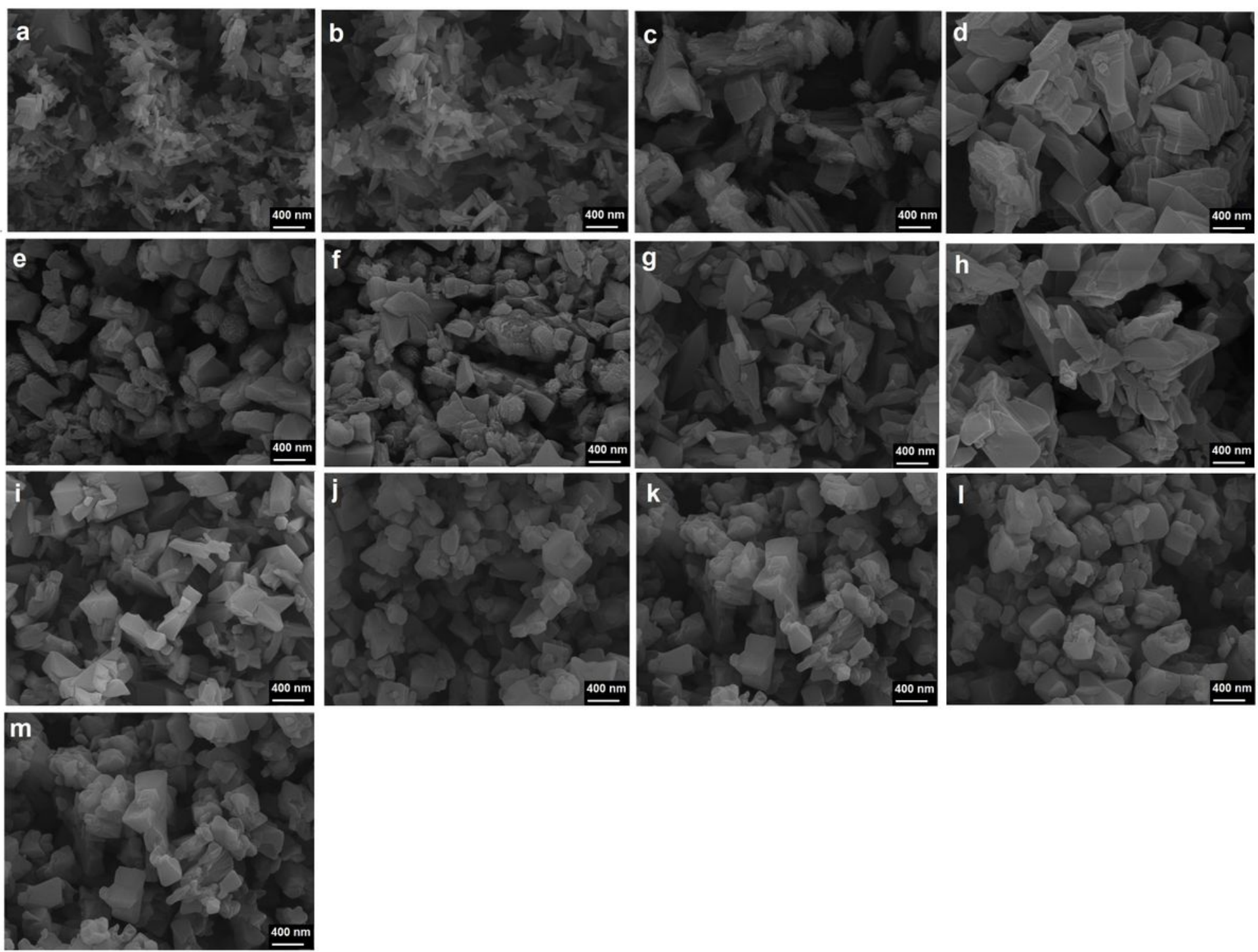

Figure 2

SEM images of the materials obtained in the synthesis of MIL-53(Al) at different temperatures and times a) $\left.\left.\left.120{ }^{\circ} \mathrm{C}-30 \mathrm{~min}, \mathrm{~b}\right) 120{ }^{\circ} \mathrm{C}-60 \mathrm{~min}, \mathrm{c}\right) 120^{\circ} \mathrm{C}-120 \mathrm{~min}, \mathrm{~d}\right) 120^{\circ} \mathrm{C}-180 \mathrm{~min}$, e) $\left.150{ }^{\circ} \mathrm{C}-30 \mathrm{~min}, \mathrm{f}\right) 150{ }^{\circ} \mathrm{C}-60$ $\min$, g) $\left.150{ }^{\circ} \mathrm{C}-120 \mathrm{~min}, \mathrm{~h}\right) 150{ }^{\circ} \mathrm{C}-180 \mathrm{~min}$, i) $\left.\left.180^{\circ} \mathrm{C}-30 \mathrm{~min}, \mathrm{j}\right) 180^{\circ} \mathrm{C}-60 \mathrm{~min} \mathrm{k}\right) 180^{\circ} \mathrm{C}-120$, I) $180{ }^{\circ} \mathrm{C}-$ 180 min, m) SO3-MIL-53(Al) 


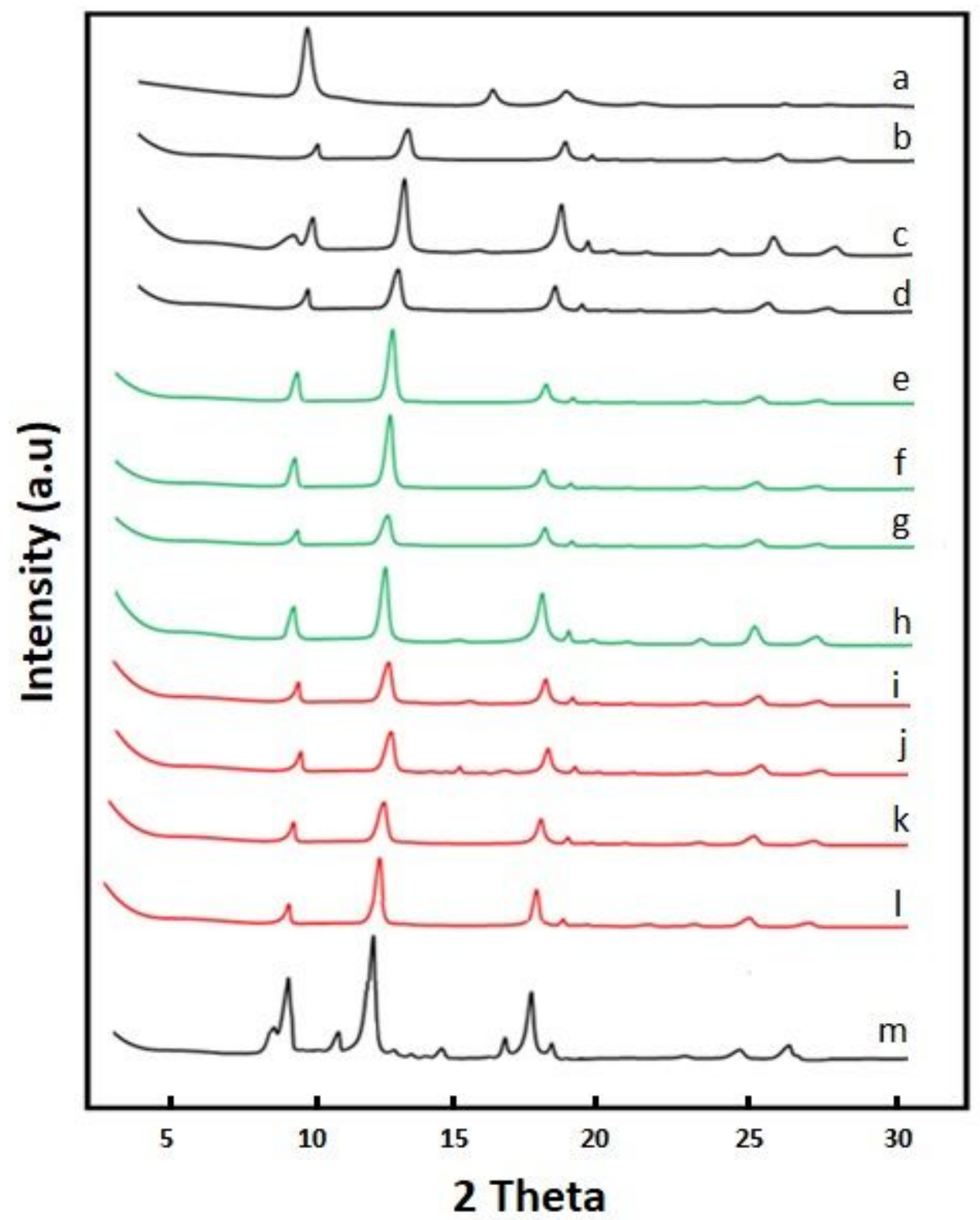

Figure 3

XRD Spectra of MIL-53 (Al) synthesis materials a) $180{ }^{\circ} \mathrm{C}-30 \mathrm{~min}$, b) $\left.180^{\circ} \mathrm{C}-60 \mathrm{~min}, \mathrm{c}\right) 180^{\circ} \mathrm{C}-120 \mathrm{~min}, \mathrm{~d}$ ) $180^{\circ} \mathrm{C}-180 \mathrm{~min}$, e) $150{ }^{\circ} \mathrm{C}-30 \mathrm{~min}$, f) $\left.150^{\circ} \mathrm{C}-60 \mathrm{~min}, \mathrm{~g}\right) 150{ }^{\circ} \mathrm{C}-120 \mathrm{~min}$, h) $150{ }^{\circ} \mathrm{C}-180 \mathrm{~min}$, i) $120^{\circ} \mathrm{C}-30$ $\min$, j) $\left.\left.120^{\circ} \mathrm{C}-60 \mathrm{~min}, \mathrm{k}\right) 120^{\circ} \mathrm{C}-120 \mathrm{~min}, \mathrm{l}\right) 120^{\circ} \mathrm{C}-180 \mathrm{~min}, \mathrm{~m}$ ) SO3-MIL-53(Al) 


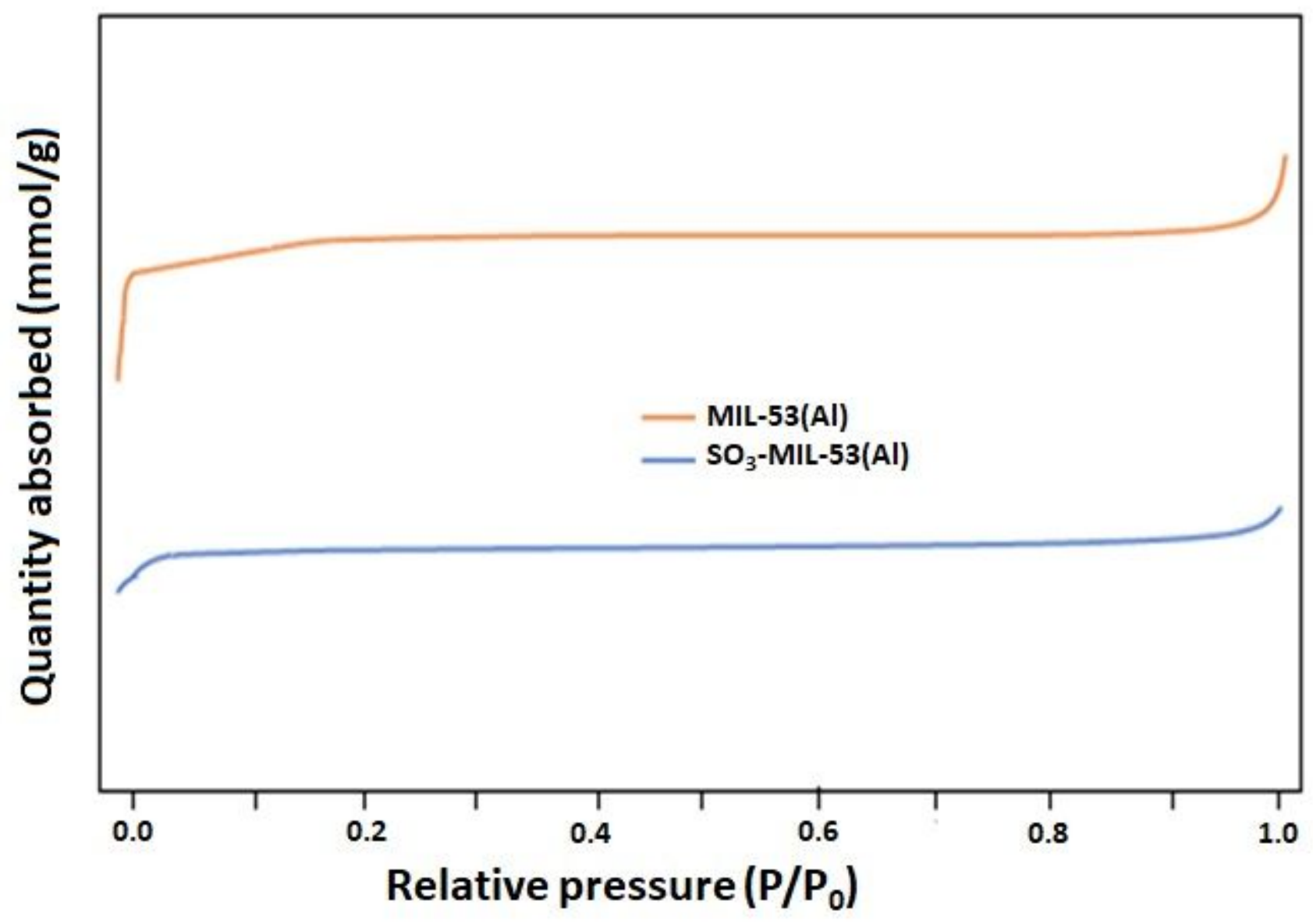

Figure 4

N2 adsorption isotherm of MIL-53(Al) and S03-MIL-53(Al) 


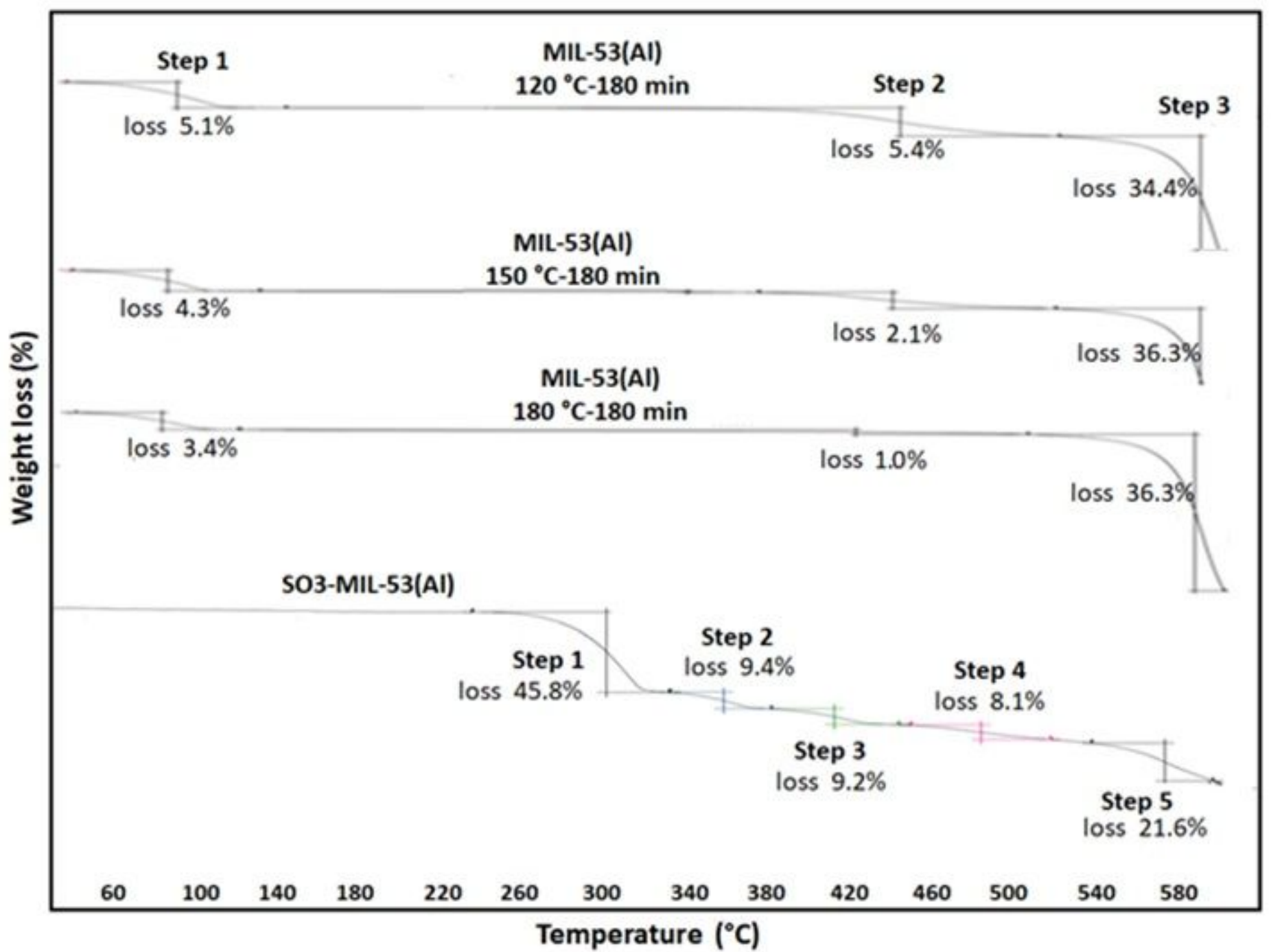

Figure 5

TGA curves of MIL-53(Al) (180 min at different temperatures) and S03-MIL-53(Al) 


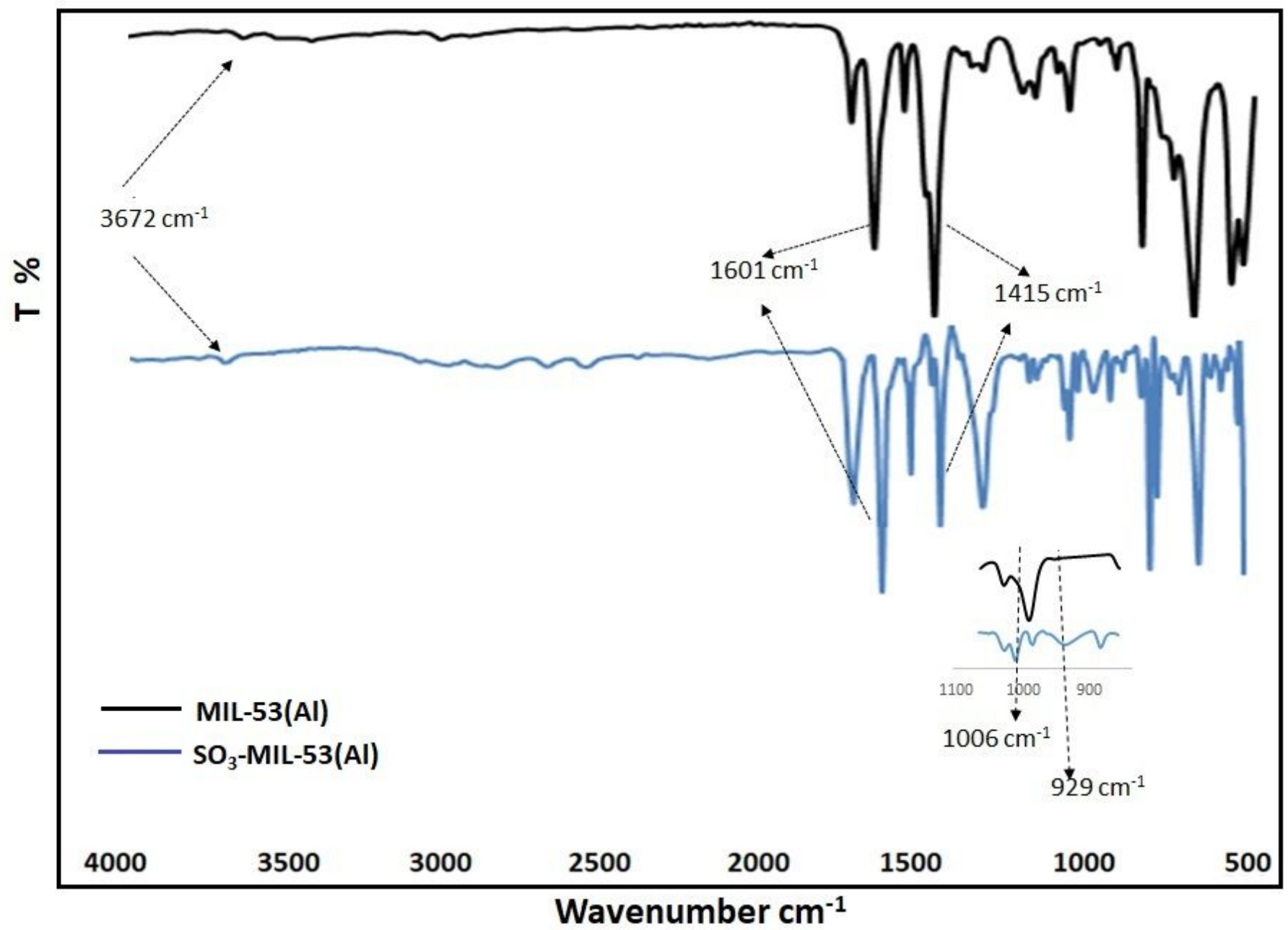

Figure 6

FTIR spectra of MIL-53(Al) and S03-MIL-53(Al) 


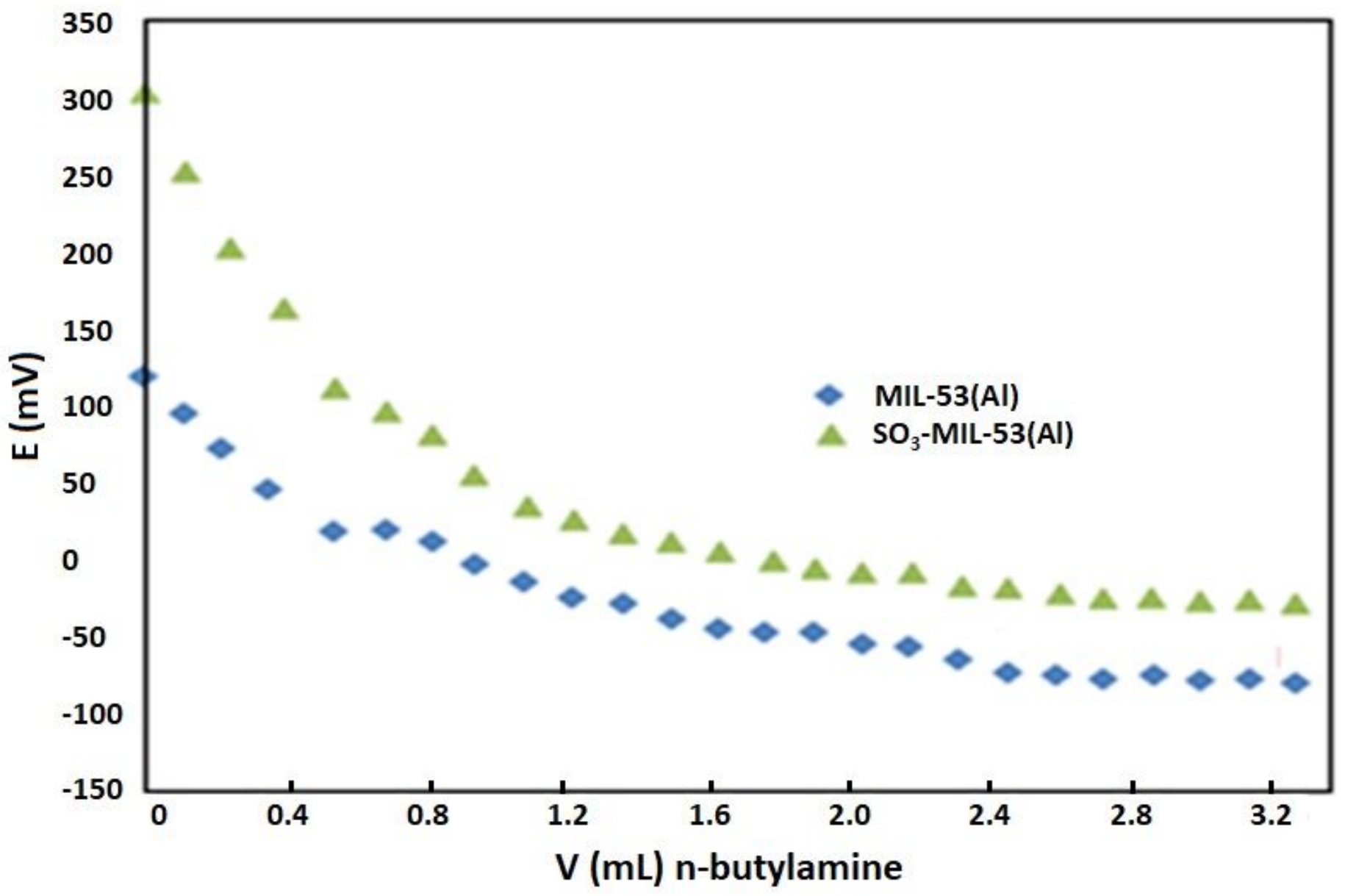

Figure 7

Potentiometric titration curves of MIL-53(Al) and S03-MIL-53(Al) 


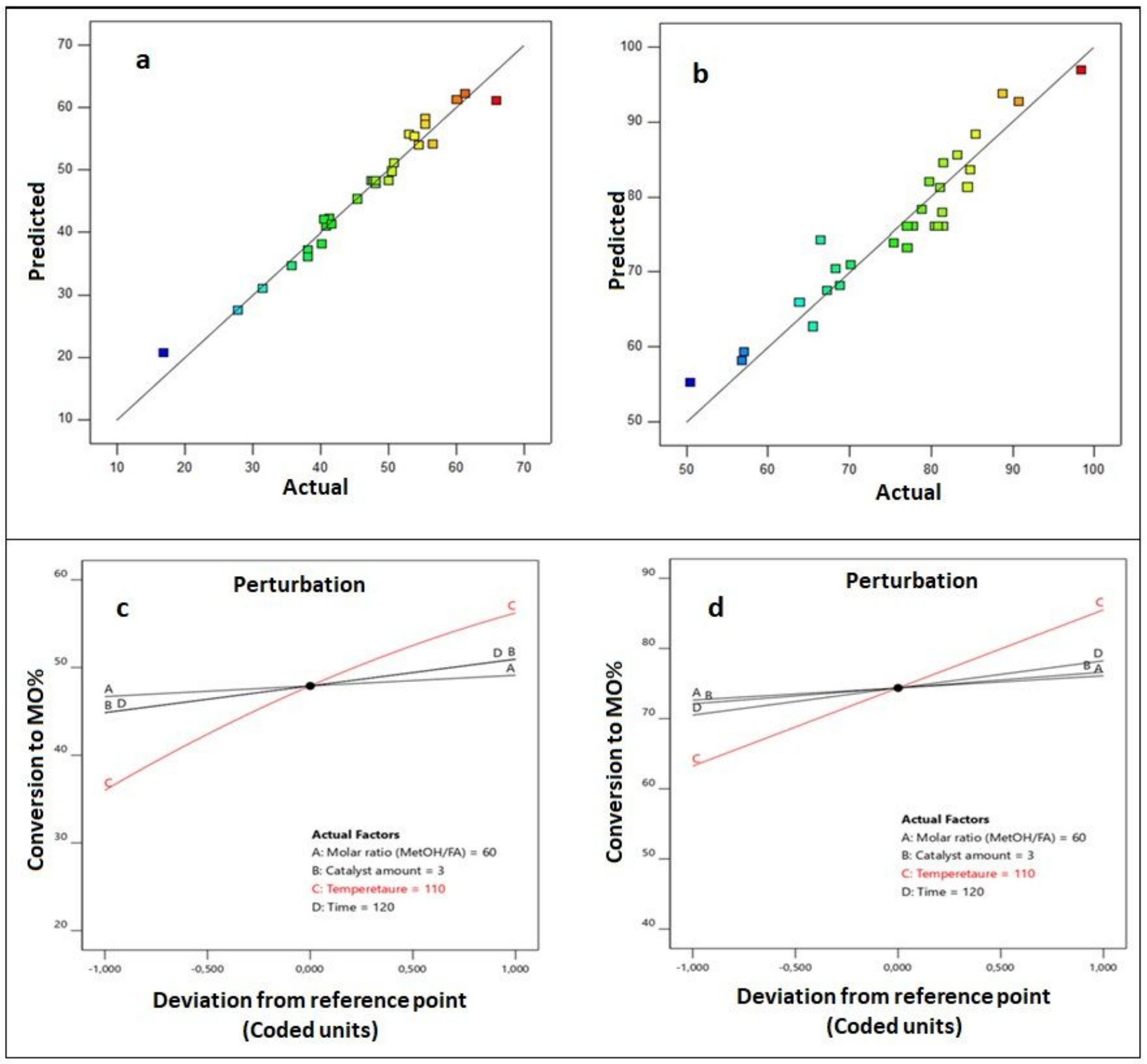

Figure 8

Comparison of experiment and model results in the CCD (a) MIL-53(Al), (b) SO3-MIL-53(AI) and the individual effect of independent parameters for the esterification of OA with catalysts (c) MIL-53(AI) and (d)SO3-MIL-53(Al) 

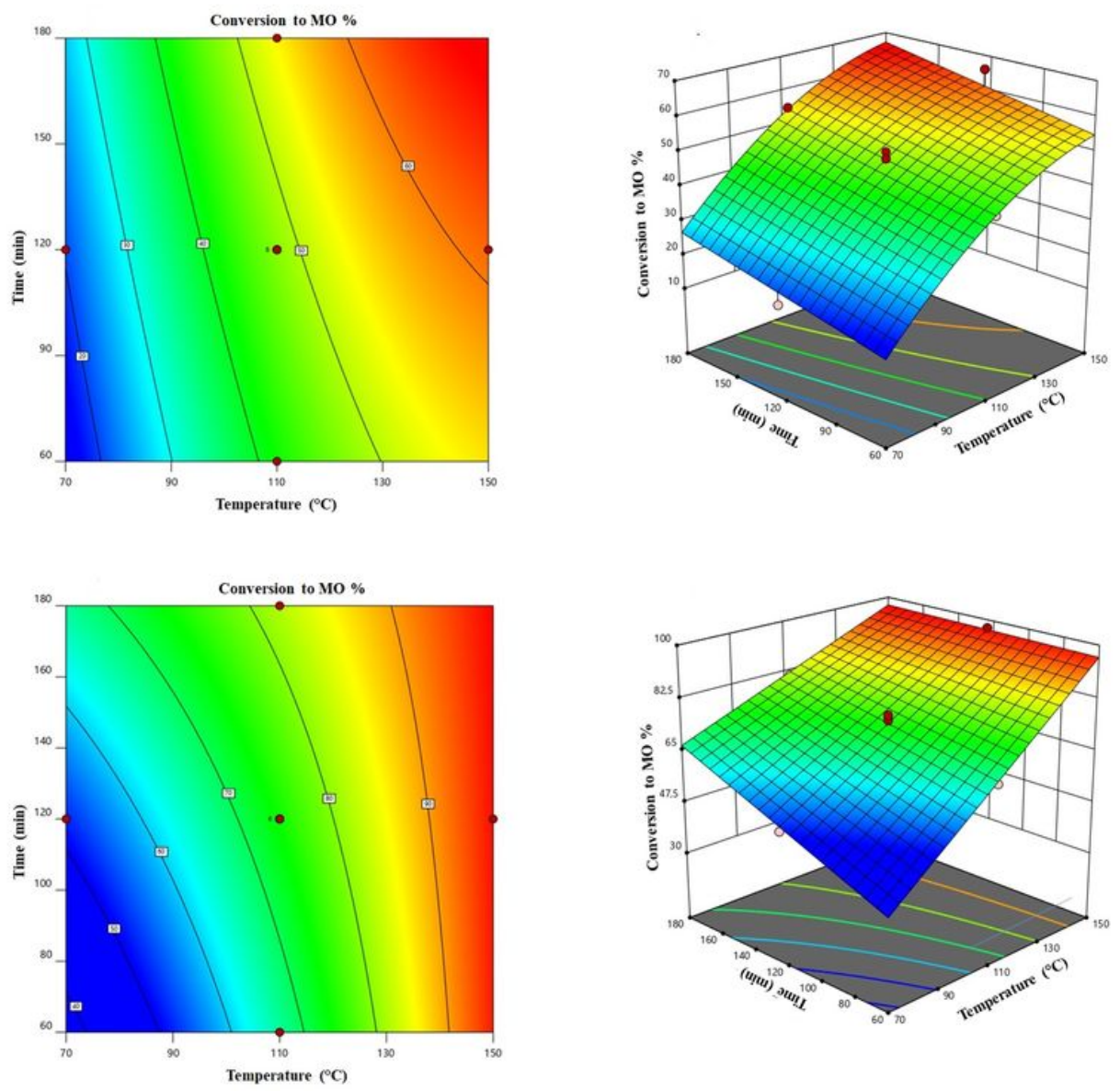

\section{Figure 9}

Contour and 3D surface plot for the effect of reaction time and temperature towards methyl oleate conversion for (a), (b) MIL-53(Al) (c),(d) SO3-MIL-53(Al) (Conditions: molar ratio/OA= $60 \mathrm{mmol} / \mathrm{mmol}$, catayst amounts $3 \%$ for MIL-53(Al) and SO3-MIL-53(Al)) 


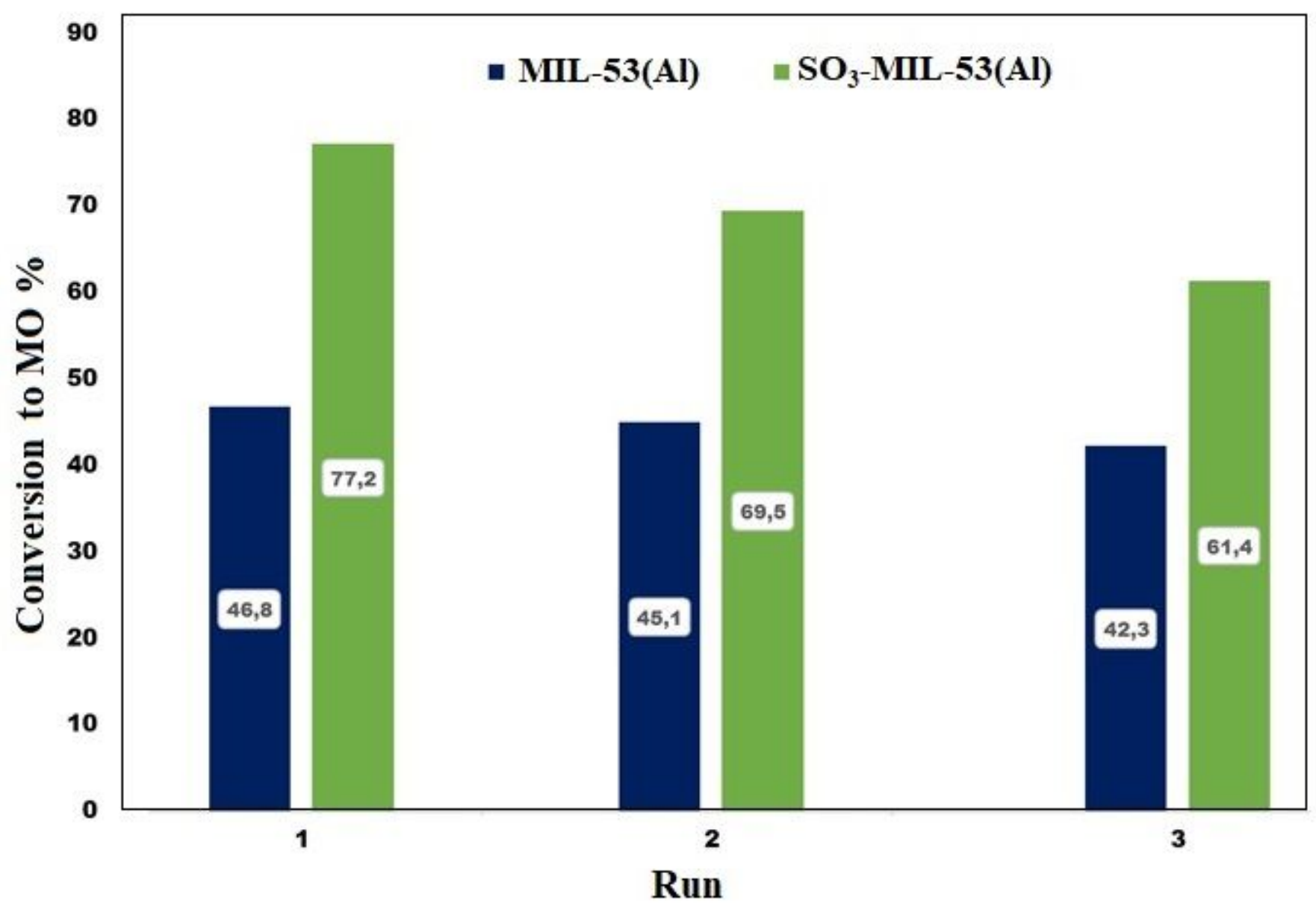

Figure 10

Reusability of MIL-53(Al) and S03-MIL-53(Al) catalysts 